\title{
Investigating the role of verbal templates in contingent capture by color
}

\author{
Diane Baier $^{1}$ (D) Ulrich Ansorge $^{1}$
}

Published online: 28 March 2019

(C) The Author(s) 2019

\begin{abstract}
To investigate if top-down contingent capture by color cues relies on verbal or semantic templates, we combined different stimuli representing colors physically or semantically in six contingent-capture experiments. In contingent capture, only cues that match the top-down search templates lead to validity effects (shorter search times and fewer errors for validly than for invalidly cued targets) resulting from attentional capture by the cue. We compared validity effects of color cues and color-word cues in top-down search for color targets (Experiment 1a) and color-word targets (Experiment 2). We also compared validity effects of color cues and color-associated symbolic cues during search for color targets (Experiment 1b) and of color-word cues during search for both color and color-word targets (Experiment 3). Only cues of the same stimulus category as the target (either color or color-word cues) captured attention. This makes it unlikely that color search is based on verbal or semantic search templates. Additionally, the validity effect of matching color-word cues during search for color-word targets was neither changed by cue-target graphic (font) similarity versus dissimilarity (Experiment 4) nor by articulatory suppression (Experiment 5). These results suggested either a phonological long-term memory template or an orthographically mediated effect of the color-word cues during search for color-words. Altogether, our findings are in line with a pronounced role of color-based templates during contingent capture by color and do not support semantic or verbal influences in this situation.
\end{abstract}

Keywords Color $\cdot$ Contingent capture $\cdot$ Attention capture $\cdot$ Search templates

To accomplish successful search for visual targets, humans set up and maintain target templates in (visual) working memory (Desimone \& Duncan, 1995; Hamker, 2004) or long-term memory (Carlisle, Arita, Pardo, \& Woodman, 2011) and compare them with the presently seen stimuli. Selection of seen stimuli for further in-depth processing is then a function of the match between stimulus features and top-down search templates (Bundesen, 1990; Duncan \& Humphreys, 1992).

However, up to now, the exact composition of search templates in visual search for colors has not been identified conclusively. Different possibilities have been discussed: Search templates might consist of feature representations in visual working memory (e.g., Baddeley, 1986; Berggren \& Eimer, 2016; Daffron \& Davis, 2016; Jenkins, Grubert, \& Eimer,

Diane Baier

diane.baier@univie.ac.at

1 Department of Basic Psychological Research and Research Methods, Faculty of Psychology, University of Vienna, Liebiggasse 5, 1010 Vienna, Austria
2017; Olivers, Peters, Houtkamp, \& Roelfsema, 2011; Vickery, King, \& Jiang, 2005), be based on verbal representations of searched-for features in (working) memory (e.g., Lupyan \& Spivey, 2010; Smyth \& Scholey, 1994; Walenchok, Hout, \& Goldinger, 2016; Wolfe, Horowitz, Kenner, Hyle, \& Vasan, 2004), or consist of semantic representations that are shared by visual objects and words (e.g., Belke, Humphreys, Watson, Meyer, \& Telling, 2008; Moores, Laiti, \& Chelazzi, 2003; Schmidt \& Zelinsky, 2009).

Here, we investigated the substrate of search templates in contingent capture by color. According to the contingentcapture theory, attentional capture by uninformative color cues depends on a match between cue color and top-down search templates (Folk \& Remington, 1998). In each trial of a contingent-capture experiment, participants search for a predefined target at one out of several possible positions. For example, participants search for a red target that in each trial can equally likely occur at one of four positions and report the target's shape. In this situation, target-similar, top-down matching cues presented prior to the targets capture attention: Valid cues (presented at target position) facilitate search as compared with invalid cues (presented away from the target). 
This validity effect is indicative of attention capture by the cue, by which valid cues capture attention to the target and invalid cues vie for attention away from the target (cf. Posner, Snyder, \& Davidson, 1980). In case of top-down matching cues, the validity effect is even found if the cue is on average not predictive of the most likely target position. This is in contrast to nonmatching cues that, if uninformative, seemingly do not capture attention and do not lead to validity effects (Folk, Remington, \& Johnston, 1992). For example, during search for red targets, uninformative red cues give rise to a validity effect, but green cues do not (Folk \& Remington, 1998).

What is true of visual search in general is also true of contingent capture by color: Currently, it is not known what kind of template is underlying the contingent-capture effect (i.e., validity effect in matching but not nonmatching conditions) by uninformative color cues. In the current study, to investigate the structure of the top-down search templates in contingent capture by color (cue) stimuli, we combined both color stimuli, symbolic stimuli associated with a color, and color-word stimuli. Words are complex stimuli, and thus it is demanding to read them when presented extrafoveally. However, humans process words presented away from the current fixation point (e.g., Bradshaw, 1974; Kliegl, Risse, \& Laubrock, 2007; Shaffer \& LaBerge, 1979; Underwood, 1977), and this is true for color words, too (e.g., Gatti \& Egeth, 1978; Kahneman \& Chajczyk, 1983). It has also been shown that words can capture attention, even if task-irrelevant (e.g., Stein, Zwickel, Kitzmantel, Ritter, \& Schneider, 2010).

In the present study, we used color words for primarily two reasons. First, color-word cues allow studying if participants use a verbal template to search for colors, to which a colorword cue denoting the searched-for color would match. Second, if participants use a semantic search template for color, again, a color-word cue denoting the searched-for color would match to the template and would capture attention. In Experiment 1b, instead of color-word cues, we used parafoveally presented symbolic shape cues associated semantically with a specific color (i.e., a heart [associated with red] or a star [associated with yellow]). Like words, these symbols would capture attention if participants use a semantic search template. In detail, color stimuli carry color information via their hues (here, as colored rings), whereas color words carry the information via their identity or meaning, and symbols via their semantic association with a specific color. If top-down templates during search for color-defined targets consist of hue representations, color-word cues and symbolic cues might be successfully ignored, even if they denote one of the searched-for colors (at least as long as they do not carry the searched-for color). However, if top-down templates during color search consist of verbal or semantic representations, color-word cues denoting the searched-for target hues or symbols being associated with the searched- for color could capture attention, just as color-ring cues of a matching color. For example, validity effects of top-down matching color-word cues could be due to the participants' subvocal rehearsal of color names during search for target colors. In addition to such a verbally mediated contingentcapture effect, semantic representations of colors could be shared among words, symbols, and sensory features (cf. Ariga \& Yokosawa, 2008; Dalrymple-Alford, 1968, 1972; Klein, 1964). According to the theory of embodied cognition (e.g., Barsalou, 1999) and to the feedback-labeling hypothesis (Lupyan, 2012), for example, conceptual semantic knowledge or even words are linked to perceptual representations, implying that color and color-word representations could reciprocally activate one another, thereby, theoretically allowing for a contingent-capture effect based on color words or symbols associated to target colors during search for color-ring targets, too. Table 1 gives an overview of the experiments and the major findings of the present study.

\section{Experiment 1a}

In Experiment 1a, to differentiate between verbal/semantic and hue-based search templates, we used both color cues and color-word cues during search for a color-ring target. Cues were not predictive of the most likely target position, and, therefore, only cues that matched the search template for the color-ring target should capture attention (Folk \& Remington, 1998; Goller, Ditye, \& Ansorge, 2016). If verbal or semantic templates play a role in visual search for colorring targets, color-ring cues as well as color-word cues should lead to contingent-capture effects: validity effects where the color-ring cue or the color-word cue matched the target color and no or smaller validity effects where the color-ring or the color-word cue did not match the target color. In contrast, if search templates are based on sensory hue representations, only color-ring cues but not color-word cues should lead to contingent-capture effects because color-word cues were presented in a nonmatching color. (The latter was necessary to prevent contingent capture based on the hues of the colorword cues alone.)

\section{Method}

Participants Twenty-one psychology students from the University of Vienna participated in Experiment 1a $\left(M_{\text {age }}=\right.$ 21.00 years, $S D_{\text {age }}=1.69$ years). The students received course credit points for their participation. Their vision and color vision were normal or corrected to normal. The treatment of all participants was in line with established ethical standards: Prior to testing, participants signed an informed consent form. They were instructed thoroughly and knew that they could abort the experiment at all times without any negative 
Table 1 Overview of designs and results of Experiments 1-5

\begin{tabular}{|c|c|c|c|c|}
\hline \multirow[b]{2}{*}{ Exp. } & \multirow[b]{2}{*}{ Cues } & \multirow[b]{2}{*}{ Targets } & \multicolumn{2}{|l|}{ Results } \\
\hline & & & RTs & $\mathrm{ACCs}$ \\
\hline $1 \mathrm{a}$ & $\begin{array}{l}\text { Colored rings \& color } \\
\quad \text { words }\end{array}$ & Colored rings & $\begin{array}{l}\text { Contingent-capture effects only by color-ring cues, } \\
\text { not by color-word cues }\end{array}$ & $\begin{array}{l}\text { Contingent-capture effects only by } \\
\text { color-ring cues, not by color-word cues }\end{array}$ \\
\hline $1 b$ & Colored rings \& symbols & Colored rings & $\begin{array}{l}\text { Contingent-capture effects by color-ring cues and } \\
\text { inversed validity effect by matching symbols }\end{array}$ & $\begin{array}{l}\text { Contingent-capture effects only by } \\
\text { color-ring cues, not by symbolic cues }\end{array}$ \\
\hline 2 & $\begin{array}{l}\text { Colored rings \& color } \\
\quad \text { words }\end{array}$ & Color words & $\begin{array}{l}\text { Validity effects only by matching but not by } \\
\text { nonmatching color-word cues, and not by } \\
\text { color-ring cues }\end{array}$ & $\begin{array}{l}\text { Validity effects by matching but not by } \\
\text { nonmatching color-word cues, and small } \\
\text { validity effect by matching color-ring } \\
\text { cues }\end{array}$ \\
\hline 3 & Color words & $\begin{array}{l}\text { Colored rings } \\
\text { \& color } \\
\text { words }\end{array}$ & $\begin{array}{l}\text { Validity effects by matching but not by nonmatching } \\
\text { color-word cues (preceding color-word targets); } \\
\text { validity effect by any color-word cues preceding } \\
\text { color-ring targets }\end{array}$ & No significant effects \\
\hline 4 & $\begin{array}{l}\text { Color words with } \\
\text { target-similar or } \\
\text { target-dissimilar font }\end{array}$ & Color words & $\begin{array}{l}\text { Validity effects by matching but not by nonmatching } \\
\text { color-word cues independent of cue-target font } \\
\text { similarity }\end{array}$ & $\begin{array}{l}\text { Validity effects by matching but not by } \\
\text { nonmatching color-word cues indepen- } \\
\text { dent of cue-target font similarity }\end{array}$ \\
\hline 5 & $\begin{array}{l}\text { Color words \& additional } \\
\text { articulatory suppression } \\
\text { or foot tapping }\end{array}$ & Color words & $\begin{array}{l}\text { Validity effects by matching but not by nonmatching } \\
\text { color-word cues independent of additional task }\end{array}$ & $\begin{array}{l}\text { Validity effects by matching but not by } \\
\text { nonmatching color-word cues indepen- } \\
\text { dent of additional task }\end{array}$ \\
\hline
\end{tabular}

Note. $\mathrm{RT}=$ reaction time, $\mathrm{ACC}=$ accuracy

consequences. The participants were neither deceived nor harmed in any way, and their well-being was monitored and ensured throughout the testing. Data collection was fully anonymous. Each student participated in only one of the following six experiments. The minimum sample size of 18 participants to detect contingent-capture effects with sufficient statistical power was estimated in a power analysis $(\alpha=.05$, $\left.\beta=.2, f^{2}=0.5\right)$. The large effect size (Cohen, 1988) was chosen in line with results from prior contingent-capture studies (cf. Büsel, Voracek, \& Ansorge, 2018a; Schoeberl, Ditye, $\&$ Ansorge, 2017).

Apparatus and stimuli Stimuli were presented on a 19-in. LCD monitor (Acer B 193), with an aspect ratio of 3:4, a resolution of 1,280 $\times 1,024$ pixels, and a vertical refresh rate of $75 \mathrm{~Hz}$. The graphic card was an Nvidia GeForce (GT 220, color 32 bit/96 DPI).

Participants sat in front of the screen, with a distance of 57 $\mathrm{cm}$. Their head rested on a chin rest. The room was indirectly and dimly lit by small USB-powered lamps behind the screens. Up to four participants were tested simultaneously. The responses were given with the two index fingers pressing keys $F$ and $J$ of a standard keyboard, respectively, depending on the orientation of the target letter $T$ (see below). The experiment was programmed and conducted using E-Prime 2.0 (Psychology Software Tools, Pittsburgh, PA).

The size of the stimuli was $1.5^{\circ} \times 1.5^{\circ}$ of visual angle, with a distance of $3.0^{\circ}$ of visual angle between stimuli. In each trial, four stimuli were presented simultaneously in the upper left, upper right, lower left, and lower right corners of a virtual square around screen center. In the target displays, one small tilted $T\left(0.5^{\circ} \times 0.5^{\circ}\right.$ visual angle $)$ was shown in white per each of the four positions (centered on these positions). Two of these letters $T$ were tilted to the left, and two were tilted to the right. Each such letter was surrounded by a colored ring.

Prior to the target displays, a cueing display was shown. In half of the trials, the cueing display consisted of four colored rings (all without letters $T$ ). The cue ring was presented as a color singleton between three color-homogenous rings. In the other half of trials, in the cueing displays, one of the four rings was replaced by a color-word stimulus that consisted of roughly the same number of pixels as a ring. To maintain as much similarity as possible between color-ring cue and colorword cue conditions, the nonsingletons in the cueing displays were colored rings in both of these conditions, and only the cues were different. See Fig. 1.

The colors of the stimuli were green (CIE L*a*b*, 73.0, $-82.7,52.9)$, blue $(73.1,15.4,-119.7)$, red $(72.8,97.3,93.8)$, and yellow $(73.0,-7.1,60.2)$. All colors were equiluminant and presented against a gray background $(85.0,-4.8,-21.5)$.

All statistical analyses were conducted using R (R Core Team, 2017) and the following packages: apa (Gromer, 2017), ez (Lawrence, 2016), ggplot2 (Wickham, 2009), and pwr (Champely, 2017).

Task and design Experiment 1a consisted of four withinsubjects variables: cue type (color-ring cue, color-word cue), cue match (matching, nonmatching), validity (valid, invalid), 
color-ring cue

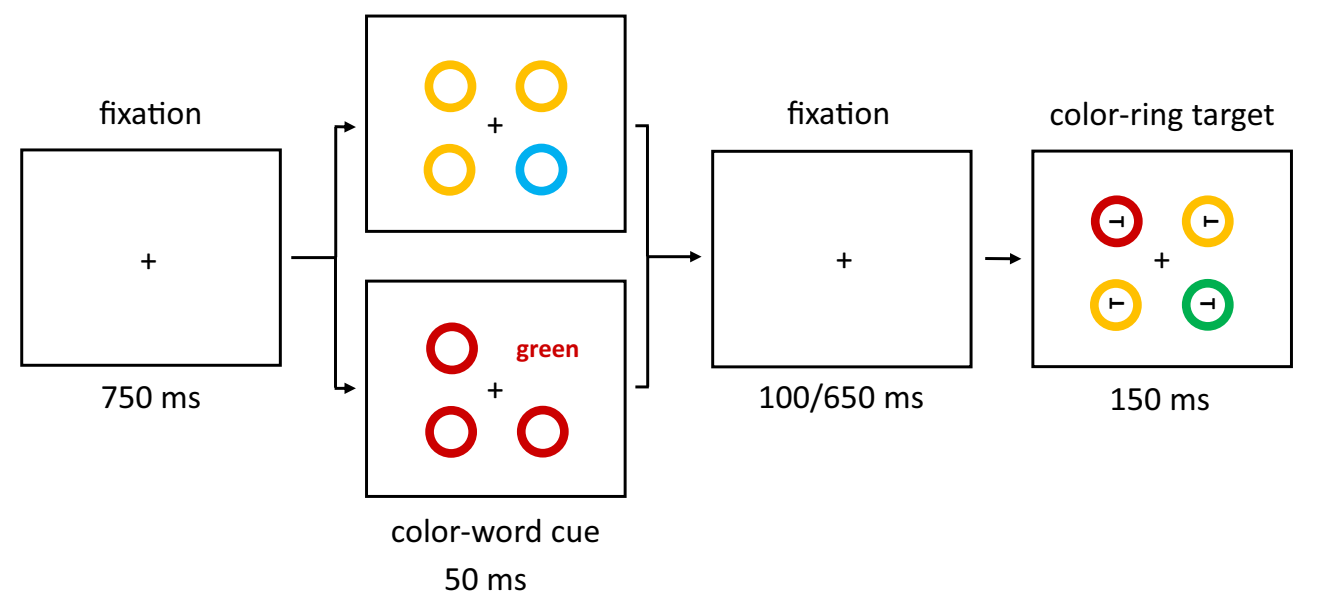

Fig. 1 Exemplary trial(s) of Experiment 1a. The target is the green ring in the rightmost box (the target remained either green or blue, varied between participants, throughout the whole experiment). Two different cue versions are displayed in the boxes second from left: valid

nonmatching color-ring cue (top); invalid matching color-word cue (bottom). In the experiment, German words were used. The arrows depict the flow of time. Stimuli are not drawn to scale. (Color figure online)

and stimulus-onset asynchrony (SOA) between cue and target $(150 \mathrm{~ms}, 700 \mathrm{~ms})$. The cue was uninformative ( $25 \%$ valid and $75 \%$ invalid), and cue and target positions were randomized and uncorrelated across trials.

The target was a predefined color ring in green or blue (balanced across participants). It was presented either among one red and two yellow distractors or among two red and one yellow distractor at the remaining target-display positions. The target was thus never a singleton. This was done to prevent top-down singleton search (Bacon \& Egeth, 1994). In contrast to the targets, all cues were singletons presented among the cueing displays' nonsingleton rings. The colorring cues stood out by their unique color among the colorhomogeneous nonsingleton rings. The German color-word cues were words that stood out by their shape and their meaning among the shape-homogeneous nonsingleton rings. In both color-ring cue and color-word cue displays, the nonsingleton rings were either all red or all yellow. The matching color-ring cue had the same color as the target. For the participants for which the target was blue, the matching color-ring cue was blue, and for the participants for which the target was green, the matching color-ring cue was green. In contrast, the nonmatching color-ring cue was blue if the target was green, and it was green if the target was blue. If a colorword cue was presented, it was of the same irrelevant font color (red or yellow) as the remaining nonsingleton rings. A potentially matching color-word cue denoted the same color as the searched-for target color (e.g., the German word grün, meaning green, if the target was green). A potentially nonmatching color-word cue denoted the same color as was used for the nonmatching color-ring cue (e.g., the German word blau, meaning blue, if the target was green). This was done to prevent that the color-word cue could have captured

attention by means of its top-down matching color or by its status as a color singleton alone.

Participants had to search for the target and respond to the orientation of the tilted $T$ inside of the target ring. Orientationto-response key mappings were counterbalanced across participants. Figure 1 shows exemplary trials of Experiment 1a.

Procedure Each trial started with a fixation cross, centrally located on the screen. After $750 \mathrm{~ms}$, the cueing display was presented. It consisted of one singleton-color-ring cue or one color-word cue and three nonsingleton rings presented for 50 ms. Stimuli in the cueing displays were pseudorandomly assigned to the four positions.

After an SOA of 150 or $700 \mathrm{~ms}$, the target display was presented. It consisted of a target and three distractors that were displayed at the same four positions for $150 \mathrm{~ms}$ (see Fig. 1). Like the cues and nonsingletons, target and distractors were pseudorandomly assigned to the four positions. The two different SOAs were chosen after Wolfe, Butcher, Lee, and Hyle (2003). The shorter SOA might facilitate the effects of color-ring cues (cf. Gibson \& Amelio, 2000), whereas the longer SOA might facilitate the effects of color-word cues, as reading words might take longer than perceiving colors.

Trials with matching and nonmatching color-ring cues and trials with potentially matching and nonmatching color-word cues were equally likely and presented in a pseudorandom sequence. Prior to data collection, participants received written and verbal instructions explaining the task and practiced until they made fewer than $20 \%$ errors. During the experiment, no feedback was provided about the correctness of the responses. Together with 768 experimental trials, the whole experiment took approximately $60 \mathrm{~min}$. 


\section{Results}

Initially, to check for advantages in perception and processing of word cues presented on the right side that could have been due to more parafoveal preview benefits for word cues on the right versus left, we conducted an analysis of variance (ANOVA), including cue-side as an independent variable. This variable did not show more cueing by word cues on the right. For all further analyses, we therefore collapsed data across cue sides.

\section{Reaction-time analysis}

Trials with false responses were removed, as well as responses faster or slower than two standard deviations from the median per person and condition (in total, 9.79\%). Although a twostandard-deviation cutoff is quite common (e.g., Ansorge, Kiss, Worschech, \& Eimer, 2011), we additionally analyzed all data with a more liberal cutoff ( \pm three $S D$ s per person per condition). The pattern of the results remains the same, except for some minor differences (for a detailed listing of the differences, refer to Appendix A). A $2 \times 2 \times 2 \times 2$ repeatedmeasures ANOVA of the correct mean reaction times (RTs), with the variables cue type (color-ring cue, color-word cue), validity (valid, invalid), cue match (matching, nonmatching), and SOA (150 ms, $700 \mathrm{~ms}$ ), was conducted. Here and in the following experiments, only the significant highest order interaction is reported. For all significant main effects and lower order interactions that were qualified by the highest order interaction, the interested reader should refer to Appendix B. A complete listing of mean correct RTs and accuracy rates for all conditions and experiments can be found in Appendix C.

Contingent-capture effects show as an interaction of validity and cue match in the ANOVA, as the validity effects are selective (only top-down matching cues lead to validity effects). To pinpoint the interaction of validity and cue match, matching valid versus invalid conditions (for which significant validity effects are expected), as well as nonmatching valid versus invalid conditions (for which no effects or same-location costs are expected) are compared in post hoc $t$ tests, here, and in the following experiments. These $t$ tests were conducted for each cue type and each SOA in turn if a significant three-way or four-way interaction indicated that this was necessary. For additional comparisons of matching valid versus nonmatching valid cues, as well as between matching invalid versus nonmatching invalid cues, please refer to Appendix D.

The ANOVA yielded a significant four-way interaction of Cue Type $\times$ Validity $\times$ Cue Match $\times \operatorname{SOA}, F(1,20)=17.75, p$ $<.001, \eta_{\mathrm{p}}^{2}=.47$ (see Fig. 2; Table 5 in Appendix C; other significant main effects and interactions are listed in Table 2 in Appendix B). For the follow-up $t$ tests, the critical alpha of $p=$ .05 was Bonferroni corrected - that is, it was divided by the number of tests (i.e., by 16), and thus alpha was .003 .
Color-ring cues The $t$ tests revealed contingent-capture effects for color-ring cues in the short SOA: faster RTs in valid (499 $\mathrm{ms})$ than in invalid $(586 \mathrm{~ms})$ trials after a matching cue, $t(20)=$ $-13.84, p<.001, d=-2.95$, and no validity effects with nonmatching cues, $t(20)=0.02, p=.982, d<0.01$. Also in the long SOA, RTs with matching color-ring cues were significantly faster in valid $(546 \mathrm{~ms})$ than in invalid $(582 \mathrm{~ms})$ conditions, $t(20)=-4.23, p<.001, d=-0.90$. Nonmatching cues did not produce any significant effects, $t(20)=-0.49, p=$ $.627, d=-0.11$.

Color-word cues Color-word cues did not show any significant effects in the post hoc tests, all nonsignificant $|t \mathrm{~s}|(20)<3.29$, all $p \mathrm{~s}>.004$, all $|d \mathrm{~s}|<0.70$.

\section{Accuracy analysis}

Per each condition, the individual rates of accurate responses were arcsine-transformed before conducting a repeatedmeasures ANOVA analogous to the one above. It showed a significant three-way interaction of Cue Type $\times$ Validity $\times$ Cue Match, $F(1,20)=23.18, p<.001, \eta_{\mathrm{p}}^{2}=.54$, that mirrored important results of the RT analysis (see Fig. 3). (For other significant main effects and interactions, refer to Table 3 in Appendix B. Table 5 in Appendix $\mathrm{C}$ shows the mean accuracy rates of all conditions.) Post hoc Bonferroni-corrected $t$ tests (alpha corrected for eight comparisons, equal to .006) examined contingent-capture and validity effects for the different cue types. Here and in the following experiments, we present comparisons between valid and invalid matching, as well as nonmatching cues. For comparisons between matching and nonmatching valid, as well as matching and nonmatching invalid cues, please refer to Appendix E.

Color-ring cues $T$ tests yielded validity effects of matching color-ring cues, with better performance in valid $(97.9 \%)$ than in invalid $(92.9 \%)$ trials, $t(20)=6.65, p<.001, d=1.42$. Validity effects were selectively present for matching cues, and nonmatching cues did not lead to a significant validity effect, $t(20)=1.22, p=.236, d=0.26$.

Color-word cues In the post hoc tests, word cues did not lead to any significant validity effects, all nonsignificant $|t \mathrm{~s}|(20)<$ 2.87, all $p \mathrm{~s}>.009$, all $|d \mathrm{~s}|<0.61$.

\section{Discussion}

In Experiment 1a, we wanted to distinguish between contingentcapture effects based on templates for sensory hues versus verbal/semantic search templates by using both color-ring and color-word cues during search for a color-ring target. As expected, the color-ring cues led to significant contingent-capture effects in the short SOA condition: Only cues in a top-down 

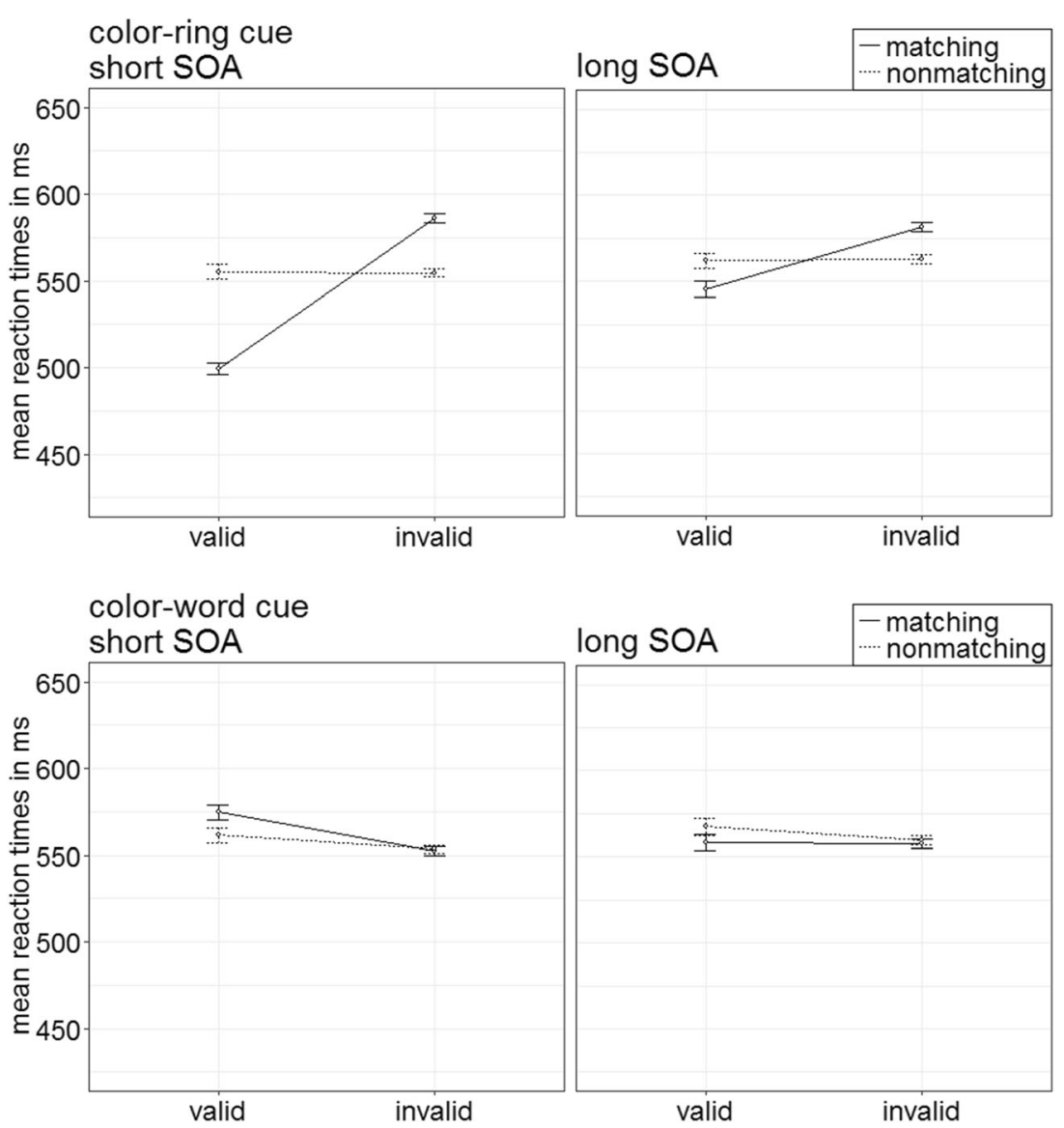

Fig. 2 Experiment 1a: Mean correct reaction times (in ms) for color-ring cues (upper panels) and color-word cues (lower panels) depending on stimulusonset asynchrony (SOA), cue match, and validity. Error bars represent average standard errors

matching color elicited validity effects - namely, faster reactions and fewer errors in valid than in invalid conditions. In the long SOA condition, the contingent-capture effects of color-ring cues were still present but less pronounced than in the short SOA condition (see also Experiment 5 of Ansorge, Priess, \& Kerzel, 2013; Gibson \& Amelio, 2000). In contrast, color-word cues led to neither contingent-capture nor to validity effects. Given that the color-word cues apparently did not capture any attention at all, the results of Experiment 1a tentatively speak for search templates consisting of sensory hue feature representations and provide no evidence for verbally or semantically mediated contingent-capture effects during search for color-ring targets. These results might be surprising, as they seem inconsistent with some other findings: For example, seeing a word alone automatically included color representations in search templates in the studies of Nako, Smith, and Eimer (2016) or R. Wu et al. (2013).

However, in Experiment 1a, the lack of capture effects by color-word cues could have been due to a failure to recognize the words. Words are complex stimuli but were presented parafoveally, and thus it might have been difficult for the participants to read them (but see, e.g., Gatti \& Egeth, 1978). In Experiment 1a, the lack of capture effects by color-word cues could have also been due to other forms of generally higher processing difficulty for word cues compared to color-ring cues. The color-word cues were written in an irrelevant and incongruent font color (red or yellow). Reading color words with a font color not matching the meaning of the color word might be difficult (Durgin, 2000; but see Stroop, 1935). Additionally, participants might have actively suppressed the processing of words due to the words' irrelevant (nonmatching) font colors. As explained in the Method section, words were presented in the same color as the distractors in the target displays. This might have increased participants' active inhibition of stimuli that carried the corresponding colors - here, of the color-word cues. Moreover, when it comes to influences on visual attention, word cues are generally less effective than picture cues (see, e.g., Nako et al., 2016; Wolfe et al., 2004; R. Wu et al., 2013).

To control for the influence of processing duration, in Experiment 1b, we used symbolic cues associated with a specific color instead of color-word cues. If the higher processing difficulty of color words in Experiment 1a prevented that we could demonstrate a semantically based capture effect, then the use of symbolic cues in Experiment $1 \mathrm{~b}$ might allow semantic effects to show, as these cues consisted of a single symbol rather than of a string of several letters. 

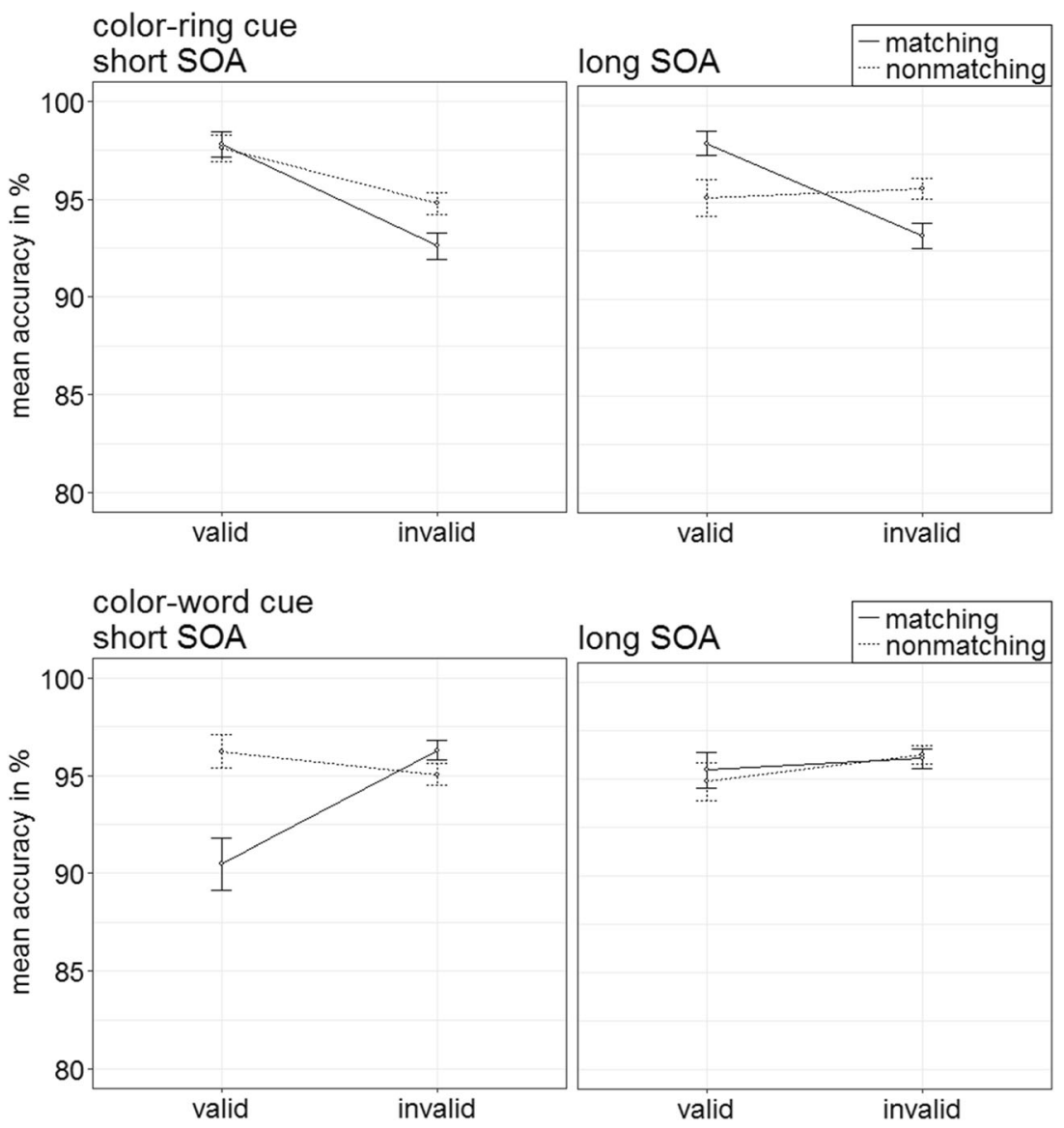

Fig. 3 Experiment 1a: Mean accuracy rates in percentages for color-ring cues (upper panels) and color-word cues (lower panels) depending on stimulusonset asynchrony (SOA), cue match, and validity. Error bars represent average standard errors

\section{Experiment 1b}

To examine the influence of semantics in top-down search templates for color, we compared color-ring cues and parafoveally presented symbolic cues in Experiment $1 \mathrm{~b}$. The symbolic cues were semantically associated with a specific color: a heart symbol for the color red and a star symbol for the color yellow. If the search templates were at least partly based on semantics, both the color-ring cues as well as the symbolic cues should capture attention-if they matched the searched-for color-and lead to contingentcapture effects.

\section{Method}

Participants In Experiment 1b, 23 psychology students of the University of Vienna participated $\left(M_{\mathrm{age}}=20.04\right.$ years, $S D_{\text {age }}=1.92$ years). Three had to be excluded due to an error rate exceeding $20 \%$.

Procedure and design We adapted the design of Experiment 1a in two ways: First, we replaced the color-word cues by symbolic cues associated with a specific color. Second, instead of green as a target color and blue as a nonmatching color (and vice versa for half of the participants), we used red as a target color and yellow as nonmatching color (and vice versa for half of the participants). We changed the color setup, as we needed symbols clearly associated with a color, and according to an online survey via Clickworker (https://www. clickworker.de), the closest associations were between red and heart (100\% accordance) and yellow and star (94\% accordance). To check if the symbols were indeed semantically associated with a color, we included a short congruency test after the main experiment, where participants had to discriminate the symbols (star or heart) by key press as fast as possible. These symbols had either a color congruent to their semantic association (red heart, yellow star) or incongruent (yellow heart, red star). We would expect faster responses in congruent than in incongruent trials (Ménard-Buteau \& Cavanagh, 1984; Naor-Raz, Tarr, \& Kersten, 2003). Every trial of the color-association test started with a fixation cross presented for $1,500 \mathrm{~ms}$, followed by the colored symbol (heart or star, in red or yellow) for $50 \mathrm{~ms}$, and a structural mask for $100 \mathrm{~ms}$. This additional task had 48 trials (including eight practice trials). 
The main experiment consisted of four within-subjects variables: cue type (color-ring cue, symbolic cue), cue match (matching, nonmatching), validity (valid, invalid), and SOA between cue and target (150 ms, $700 \mathrm{~ms}$ ). Note that only one level of the factor cue type was changed compared with Experiment 1a (symbolic cues instead of color-word cues). The cueing displays with color-ring cues showed four colored rings: one colorring cue in the target color or nonmatching color (red or yellow) and three irrelevant distractors (color rings, all either green or blue). In the condition with symbolic cues, the only difference was that instead of the color-ring cue in red or yellow, a heart or star was presented in the same color as the three irrelevant distractor rings (blue or green). This symbol could either semantically match the target color (heart for a red target, star for a yellow target) or not (star for a red target, heart for a yellow target). See Fig. 4 for an exemplary trial of Experiment $1 \mathrm{~b}$. Target colors were counterbalanced across participants (each participant searched for either red or yellow targets throughout the whole experiment). We expected contingent-capture effects for both color-ring cues and symbolic cues if search templates are at least partly based on semantic representations.

\section{Results}

\section{Reaction-time analysis}

Trials with false responses were removed, as well as responses faster or slower than two standard deviations from the median per person and condition (in total 13.85\%). A $2 \times 2 \times 2 \times 2$ repeated-measures ANOVA of the correct mean reaction times (RTs), with the variables cue type (color-ring cue, symbolic cue), validity (valid, invalid), cue match (matching, nonmatching), and SOA (150 ms, $700 \mathrm{~ms}$ ), was conducted. It showed a significant four-way interaction of Cue Type $\times$ Validity $\times$ Cue Match $\times$ SOA, $F(1,19)=10.15, p=.005, \eta_{p}^{2}=.35$ (see Fig. 5; Table 6 in Appendix C). For a complete listing of all significant interactions and main effects, see Table 2 in Appendix B.

We calculated post hoc $t$ tests examining contingentcapture and validity effects for the different cue types and SOAs (Bonferroni correction of the critical alpha, $p=.003$ ).

Color-ring cues We found contingent-capture effects for colorring cues in the short SOA: faster RTs in valid (525 ms) than in invalid (643 ms) trials after a matching cue, $t(19)=-8.04, p<$ $.001, d=-1.75$, and no validity effects with nonmatching cues, $t(19)=-0.06, p=.951, d<-0.01$. Accordingly, in the long SOA, matching cues led to faster RTs if valid (579 ms) than if invalid $(629 \mathrm{~ms}), t(19)=-4.81, p<.001, d=-1.05$, and no difference was found for nonmatching cues, $t(19)=$ $0.99, p=.334, d<0.22$.

Symbolic cues In the short SOA, invalid matching cues led to significantly faster reactions $(580 \mathrm{~ms})$ than valid matching cues $(606 \mathrm{~ms}), t(19)=3.72, p=.001, d=0.81$. Nonmatching cues did not produce a significant effect, $t(19)$ $=2.81, p=.011, d=0.61$. In the long SOA, symbolic cues did not show any significant validity effects in the post hoc tests, all $|t \mathrm{~s}|(19)<0.77$, all $p \mathrm{~s}>.448$, all $|d \mathrm{~s}|<0.17$.

\section{Accuracy analysis}

Before conducting a repeated-measures ANOVA analogous to the one above, the individual accuracy rates were arcsine transformed per condition. The ANOVA yielded a significant fourway interaction of Cue Type $\times$ Validity $\times$ Cue Match $\times$ SOA,

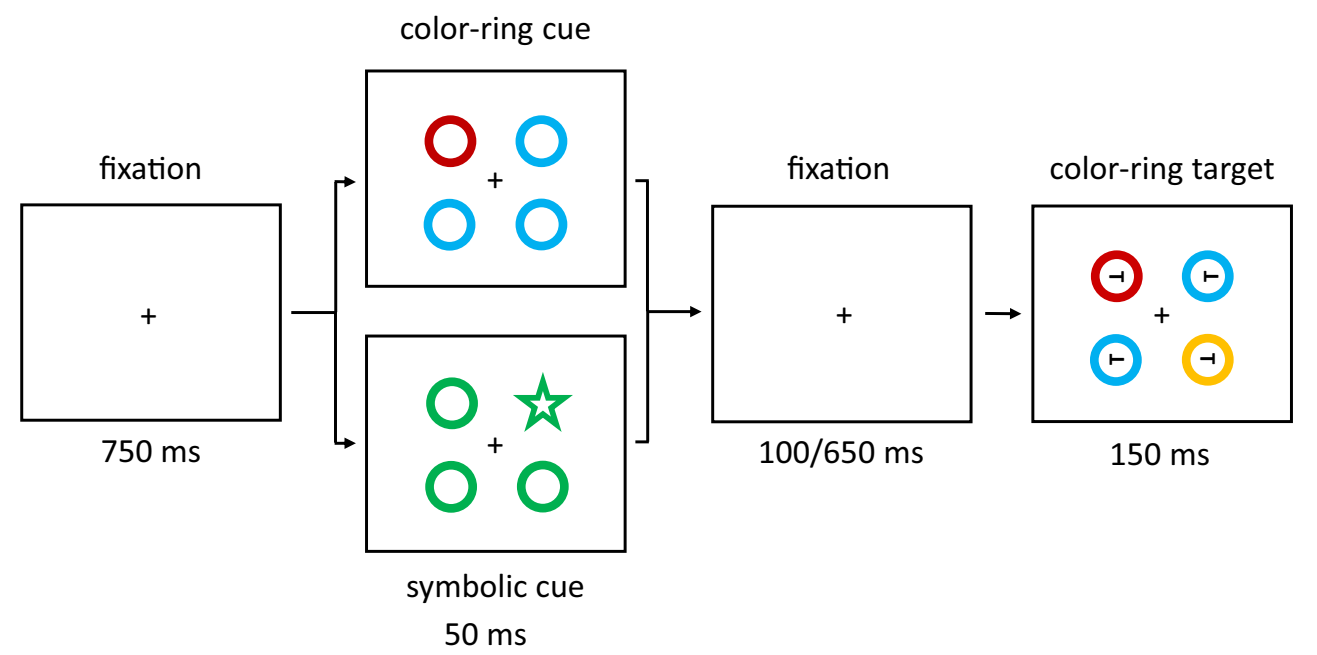

Fig. 4 Exemplary trial(s) of Experiment 1b. The target is the red ring in the rightmost box (the target remained either red or yellow, varied between participants, throughout the whole experiment). Two different cue versions are displayed in the boxes second from left: valid matching

color-ring cue (top); invalid nonmatching symbolic cue (bottom). The arrows depict the flow of time. Stimuli are not drawn to scale. (Color figure online) 

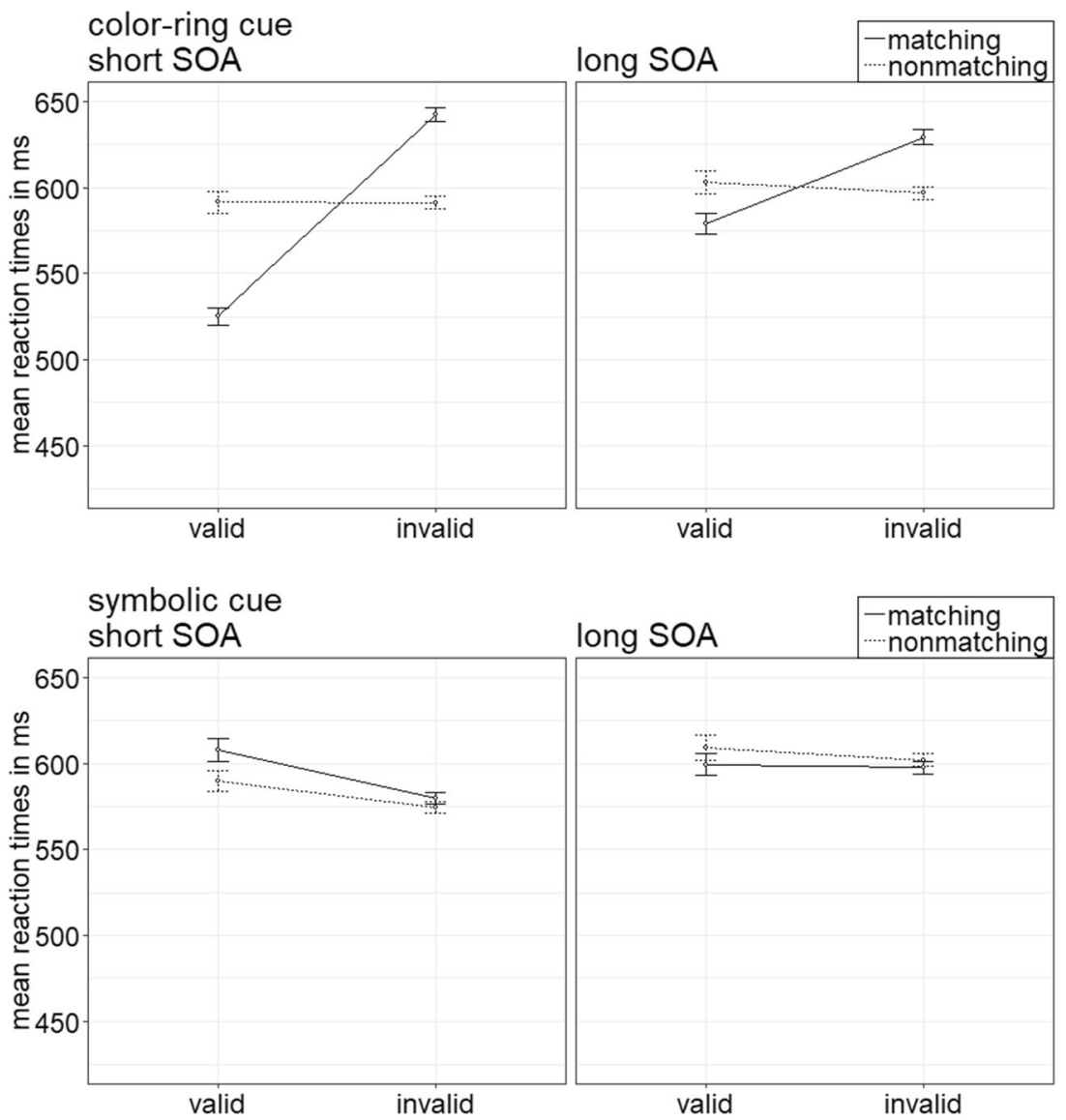

Fig. 5 Experiment 1b: Mean correct reaction times (in ms) for color-ring cues (upper panels) and symbolic cues (lower panels) depending on stimulusonset asynchrony (SOA), cue match, and validity. Error bars represent average standard errors

$F(1,19)=5.41, p=.031, \eta_{\mathrm{p}}^{2}=.22$ (see Fig. 6; Table 6 in Appendix C). For a complete listing of all significant interactions and main effects, see Table 3 in Appendix B. Post hoc $t$ tests (with alpha Bonferroni corrected, equal to .003) examined contingent-capture and validity effects for the different cue types.

Color-ring cues $T$ tests revealed a contingent capture effect of color-ring cues in the short SOA condition: better performance in valid $(96.9 \%)$ than in invalid $(88.7 \%)$ trials, $t(19)$ $=7.28, p<.001, d=1.59$, selectively for matching cues, and no significant difference between nonmatching valid and invalid cues, $t(19)=3.06, p=.006, d=0.67$. In the long SOA, no validity effects were found, all $|t \mathrm{~s}|(19)<1.79$, all $p \mathrm{~s}>.102$, all $|d \mathrm{~s}|<0.37$.

Symbolic cues In the post hoc tests, symbolic cues did not lead to any significant validity effects, all nonsignificant $|t \mathrm{~s}|(19)<$ 2.56 , all $p \mathrm{~s}>.019$, all $|d \mathrm{~s}|<0.56$.

\section{Analysis of association between symbol and color}

To check for congruency effects between symbol and associated color, we conducted a $t$ test comparing RTs and accuracies to symbols in congruent versus incongruent colors. Only correct responses as well as responses within two standard deviations from the mean per person per condition were included in the analysis of the RTs (removal in total: 14.64\%). Reactions were significantly faster in congruent $(535 \mathrm{~ms})$ than in incongruent (553 ms) conditions, $t(19)=-2.21, p=.040, d$ $=-0.48$. Regarding accuracies, participants made fewer errors for congruently $(6.75 \%)$ than for incongruently $(7.75 \%)$ colored symbols. However, this difference is not significant, $t(19)$ $=0.25, p=.606, d=0.11$.

\section{Discussion}

In Experiment 1b, we presented color-ring cues and symbolic cues to find out if search templates for a color rely only on feature representations (hue) or are influenced by semantics. We found significant contingent-capture effects for color-ring cues: validity effects for top-down matching cues, no effects for nonmatching cues. The symbolic cues, however, did not produce classic contingent-capture effects, although their semantic association with a specific color was verified by congruency effects in an additional block at the end of the experiment. This would again argue for solely feature-based 

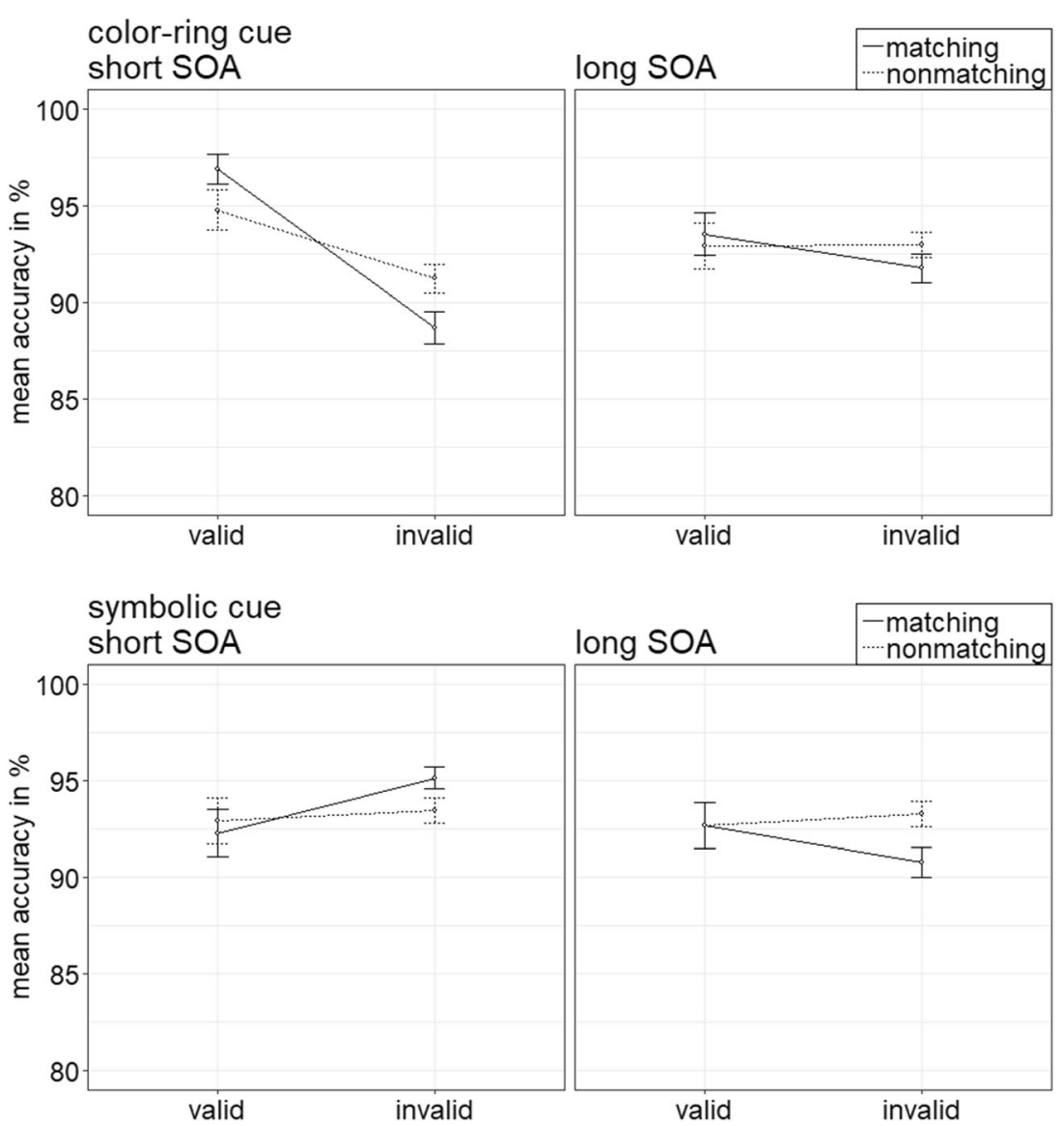

Fig. 6 Experiment 1b: Mean accuracy rates in percentages for color-ring cues (upper panels) and symbolic cues (lower panels) depending on stimulusonset asynchrony (SOA), cue match, and validity. Error bars represent average standard errors

templates. However, in the RTs of the short SOA condition, an inversed validity effect of matching symbolic cues was significant: faster reactions after an invalid than a valid cue. This might be due to our design, where all symbols were presented in an irrelevant color (either green or blue), and, therefore, a perceptual inhibition of incongruently colored objects (e.g., a green star; Ménard-Buteau \& Cavanagh, 1984) occurred. As this inhibition only arose for semantically matching symbols, semantics seem to be involved. However, the inverse validity effect of the matching symbolic cues might have had more to do with the fact that participants generally inhibited the elicitation of a color representation by the symbols that would have not been the target color in half of the trials than with the search templates for the color targets themselves. Such an active suppression of the symbols would then have had the unwanted consequence that processing of a target of the same color and at the same position as the symbolic cue would have suffered. Clearly, such an inhibition suggested by the symbolic cues would not be evidence that search for the color targets is based on a semantic template.

As not only the color-word cues in Experiment 1a but also the symbolic cues in Experiment $1 \mathrm{~b}$ did not lead to classic contingent-capture effects, it is unlikely that the higher processing difficulty of words in Experiment 1a caused the lack of effects. This is not to deny the possibility that top-down search could be based on semantics in other instances of visual search. Instead, we think that some characteristic of the contingent-capture protocol, such as the use of uninformative cues to measure the capture of attention, might have been responsible for why participants did not use a semantic search template in Experiments 1a and 1b. To note, during search for hue-defined targets, a hue-based template would have allowed finding the targets and successfully ignoring all color-word cues - a strategy that would have made sense given that all cues were uninformative (cf. Mast \& Frings, 2014). In fact, some researchers argued that cueing effects by uninformative top-down matching cues are just residual capture withstanding the participants' general suppression of any uninformative cue, be it a nonmatching or a matching cue (Fuchs, Theeuwes, \& Ansorge, 2013). In other words, whether participants use or do not use a semantic template might also depend on the details of the experimental protocol.

To control for these influences, as well as for those of wordcolor inconsistency, the potentially longer processing time for words than for colors, the potential difficulty of reading parafoveally presented words, and to test if verbal or semantic representations could at least in principle account for contingentcapture effects by color (cue) stimuli, in Experiment 2, we used 
color-word targets instead of color-ring targets. With color-word targets, color-word cues were task relevant and should be included in the search templates. As long as parafoveally presented words in the current study can be read at all, this manipulation should ensure that a validity effect can be measured at least with the matching color-word cues, even if other factors, such as word-font color inconsistency and the irrelevance of the wordcues' font color would invite less processing of the color-word cues. During search for color-word targets, we can also test if color-ring cues capture attention if their color hue corresponds to the meaning of the searched-for color-word target.

\section{Experiment 2}

To examine top-down search templates, in Experiment 2, we again compared color-ring and color-word cues. To avoid that participants disregarded color-word cues as irrelevant in all conditions, we replaced the color-ring targets of Experiment 1a with color-word targets. If search templates can, at least in principle, be set up for words, and parafoveally presented words can be read to a sufficient extent, then color-word cues should elicit validity effects, at least where the color-word cues corresponded to the color-word targets, and maybe not, or less so, where the color-word cues do not correspond to the searched-for colorword targets. Furthermore, if search for colors can, in principle, be carried out by verbal or semantic search templates, then color-ring cues with a color matching versus not matching the meaning of the color-word targets might again show contingentcapture effects. However, if successful selection of cues by their colors critically depends on visual search templates for sensory hue features, then color-ring cues with a hue matching versus not matching the meaning of the color-word targets might not show a contingent-capture effect, and only matching color-word cues might lead to validity effects.

\section{Method}

Participants Twenty psychology students $\left(M_{\text {age }}=23\right.$ years, $S D_{\text {age }}=3.43$ years) of the University of Vienna participated in Experiment 2. Two students had to be excluded due to an error rate exceeding $20 \%$.

Procedure and design The major modifications concerned the target displays: Participants searched for a predefined colorword target instead of a colored ring. Half of the participants searched for the target word blue, and the other half searched for the target word green. In addition to the color-word target, three color-word distractors (denoting the irrelevant colors red and yellow) were presented simultaneously. In the target displays, the font color of all color words, target and distractors, was the same and irrelevant. In half of the trials, all words in the target displays were red, and in the other half of the trials all words in the target displays were yellow. In addition, to prevent shape-singleton search and ensure that participants had to read the color-word targets, either two of the target displays' distractor words read yellow and one read red, or two of the distractor words read red and one read yellow. Finally, in the target displays, all color words were presented slightly above the center of each potential target position, and all tilted $T$ s were shown slightly below the center of each corner of the virtual square surrounding the screen center, as to allow for a good view of color words and tilted $T$ s presented at the same time. Everything else, including the different exact types of cueing displays, remained unchanged from Experiment 1a (see Fig. 7).

\section{Results}

\section{Reaction-time analysis}

Errors were excluded, and RTs trimmed by the same criterion as in the prior experiments (in total 12.33\%). A repeatedmeasures ANOVA, with the variables cue type (color-ring cue, color-word cue), validity (valid, invalid), cue match (matching, nonmatching), and SOA (150 ms, $700 \mathrm{~ms}$ ), yielded a significant three-way interaction of Cue Type $\times$ Validity $\times$ Cue Match, $F(1,17)=21.72, p<.001, \eta_{\mathrm{p}}^{2}=.56$ (see Fig. 8). (For the remaining significant main effects and interactions, refer to Table 2 in Appendix B. For a complete listing of the mean correct RTs, see Table 7 in Appendix C.) Bonferronicorrected post hoc $t$ tests for eight different comparisons (alpha $=.006$ ) were conducted.

Color-word cues We start with the tests of the color-word cue that now revealed a significant validity effect for the matching word cues, $t(17)=-5.00, p<.001, d=-1.15$, and an inverse validity effect for nonmatching color-word cues, $t(17)=4.85$, $p<.001, d=1.11$. This inverse validity effect for nonmatching word cues corresponds to a same-location cost and is a relatively common finding in contingent-capture experiments with featureheterogeneous target displays, as were also used here (see Carmel \& Lamy, 2015; Kerzel, 2019; Schoeberl et al., 2017).

Color-ring cues In the post hoc tests, color-ring cues did not lead to any significant effects, all nonsignificant $|t s|(17)<$ 3.12, all $p \mathrm{~s}>.006$, all $|d \mathrm{~s}|<0.72$.

\section{Accuracy analysis}

Arcsine-transformed accuracy rates were submitted to a repeated-measures ANOVA similar to the one above. It showed a significant two-way interaction of Validity $\times$ Cue Match, $F(1$, 17 ) $=28.36, p<.001, \eta_{\mathrm{p}}^{2}=.63$ (see Fig. 9). (See also Table 3 in Appendix B for further significant effects, and Table 7 in Appendix $\mathrm{C}$ for a complete list of the mean accuracy rate values.) 
color-ring cue

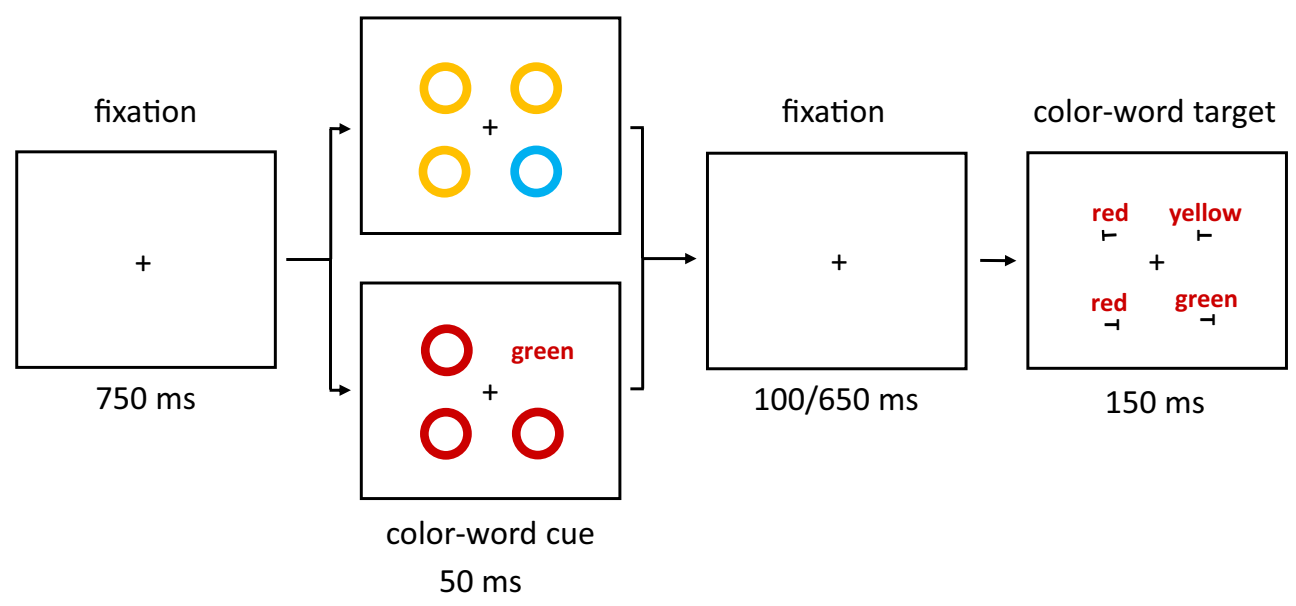

Fig. 7 Exemplary trial(s) of Experiment 2. The target is the color word green in the rightmost box (the target word remained either green or blue, varied between participants, throughout the whole experiment). Two different cue versions are displayed in the boxes second from left: valid

nonmatching color-ring cue (top); invalid matching color-word cue (bottom). The arrows depict the flow of time. Stimuli are not drawn to scale. (Color figure online)
Color-word and color-ring cues This time, data were not split up for cue type, as cue type did not significantly modulate the Validity $\times$ Cue Match interaction. With matching cues,
Bonferroni-corrected post hoc $t$ tests for four comparisons $($ alpha $=.013)$ yielded significant validity effects, $t(17)=$ $3.29, p=.004, d=0.75$, with better performance in valid
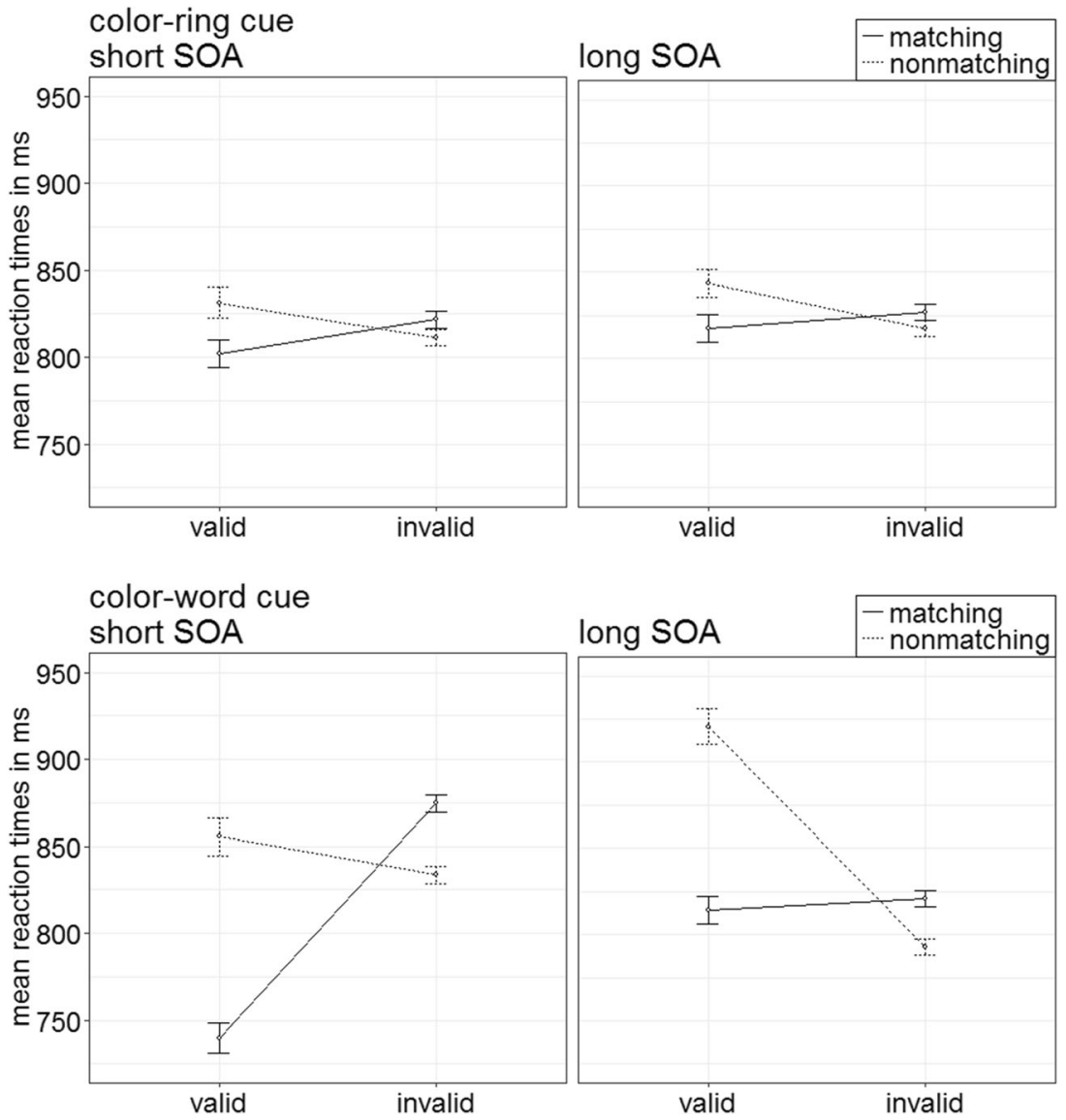

Fig. 8 Experiment 2: Mean correct reaction times (in ms) for color-ring cues (upper panels) and color-word cues (lower panels) depending on stimulusonset asynchrony (SOA), cue match, and validity. Error bars represent average standard errors 

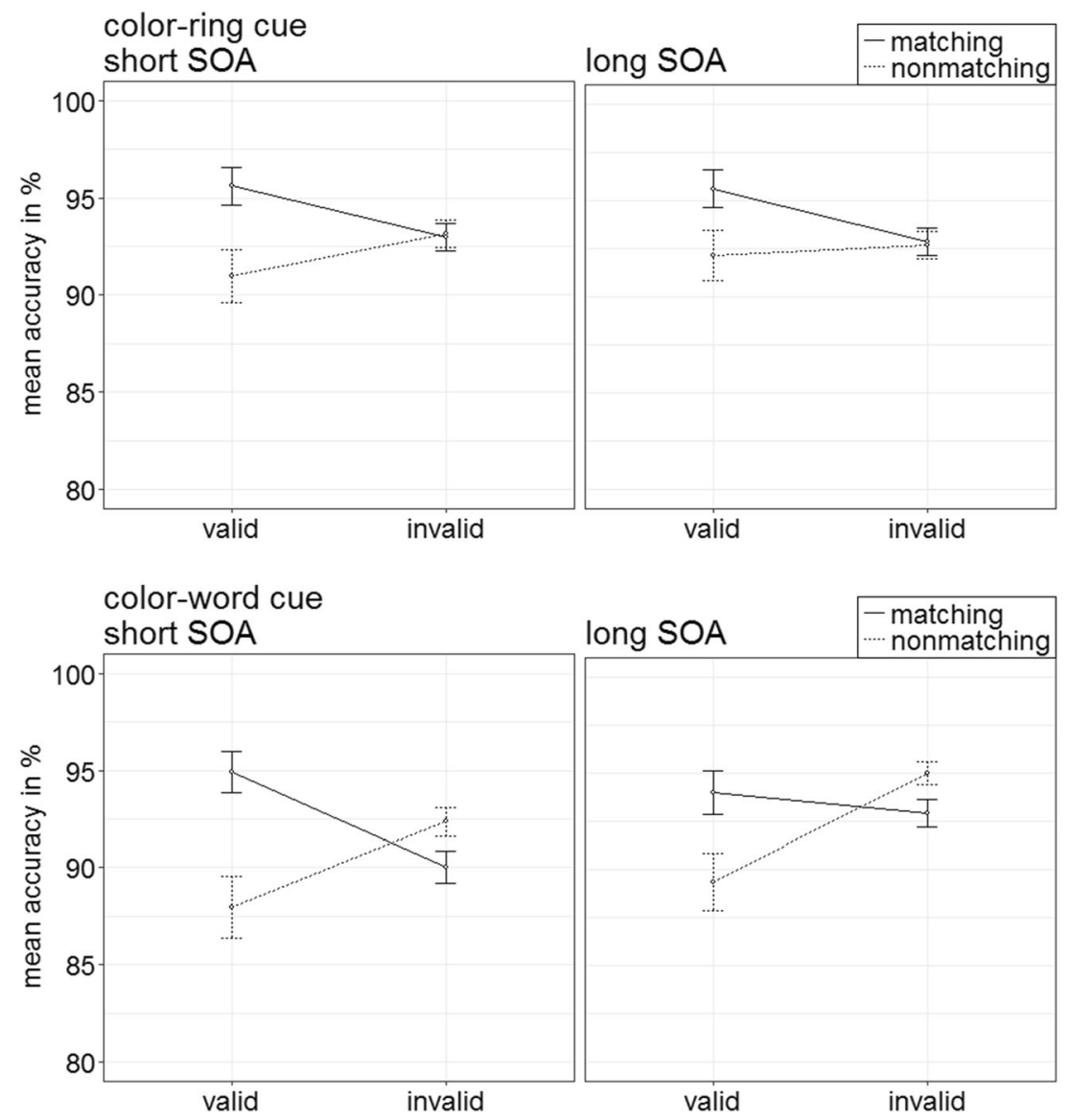

Fig. 9 Experiment 2: Mean accuracy rates in percentages for color-ring cues (upper panels) and color-word cues (lower panels) depending on stimulusonset asynchrony (SOA), cue match, and validity. Error bars represent average standard errors

$(95.0 \%)$ than invalid $(92.2 \%)$ trials. With nonmatching cues, performance was better in invalid $(93.3 \%)$ than in valid $(90.1 \%)$ conditions, $t(17)=-3.97, p=.001, d=-0.91$.

\section{Discussion}

In Experiment 2, matching color-ring cues preceding colorword targets only elicited a small validity effect in the accuracies, ${ }^{1}$ but they did not elicit any validity effects in the RTs. The features of the color-ring cues were thus apparently too dissimilar to the templates by which participants searched for the color-word targets to reliably capture attention, thus confirming a major conclusion of Experiment 1: During topdown contingent capture, selection of color-ring cues mostly is not brought about by verbal/semantic templates.

\footnotetext{
$\overline{1}$ This comparison is an additional analysis, as the significant main effect of validity is a lower order effect and cannot be interpreted as part of the omnibus ANOVA. The corresponding validity effect of color-ring cues on accuracies during search for color-word targets might be due to the activation of sensory representations (here, of colors) during reading or processing of color-word target meanings (as required per task).
}

In contrast, matching color-word cues preceding colorword targets elicited validity effects in RTs and accuracy rates, whereas nonmatching color-word cues prompted a samelocation cost. Together, these effects prove that participants were able to read the parafoveally presented color-word cues or were at least able to identify some specifying features of the words, for example, specific shapes or letters. As matching cue and target words were also graphically similar to one another, the validity effects of the matching word cues might have also been due to a template for letters or for shapes. We picked up on the question of the exact reason for validity effects by matching color-word cues in Experiments 4 and 5 .

For the time being, be this as it may. Importantly, the cueing effects of the matching words in Experiment 2 also demonstrated that the lack of any validity effect by the color-word cues in Experiment 1a was neither due to the inhibition of the irrelevant (nonmatching) color-word cues' fonts, nor to the inconsistency between word meaning and font color, as both of these influences were present in Experiment 2, too.

We also found a same-location cost by the nonmatching color-word cues. Same-location costs are relatively common during search for color targets in heterogeneous target displays (cf. Eimer, Kiss, Press, \& Sauter, 2009; Lamy, Leber, \& Egeth, 
2004), as were used here, although an agreement regarding their explanation could not be reached yet (cf. Carmel \& Lamy, 2015). It is being discussed if same-location costs reflect an initial attentional capture and subsequent rapid disengagement of attention (Belopolsky, Schreij, \& Theeuwes, 2010), a successful preemptive suppression of attentional capture (e.g., Eimer et al., 2009), more or less object-updating costs (e.g., Carmel \& Lamy, 2014; see also Enns, Lleras, \& Moore, 2009), or a mixture of (some of) these effects (Schoeberl et al., 2017). However, in the current study, which exact mechanism was responsible for the same-location costs in nonmatching color-word cue conditions was peripheral to the major research questions.

\section{Experiment 3}

In Experiment 3, we put the hypothesis that verbal or semantic templates could be involved in contingent capture during color search to one more test. It is plausible that participants have used different top-down search sets in Experiments 1 and 2, as in each experiment only one type of stimulus was relevant for the search (either hue or color word) and as all cues were uninformative. Thus, the use of a search template for only hues in Experiments 1a and $1 \mathrm{~b}$ or only words in Experiment 2 would have allowed for ignoring of the respective alternative cue type easily (i.e., word cues during search for hue targets and color-ring cues during search for word targets). In Experiment 3, to ensure that both stimulus types are relevant for the target search at the same time and thus encouraging the use of semantic templates to cover both target types, we presented both color and color-word targets that were pseudorandomly intermixed within the same blocks. If color-word cues lead to contingent capture effects regardless of the target type, we can conclude that participants' search was based on semantic or verbal templates and the lack of such influences in Experiments 1 and 2 was due to the missing incentive for including higher level semantic processes in their search. Another possibility would be that both stimulus types - color-defined rings and verbally or semantically defined color words-are included in the top-down search templates. Studies have shown that two different features (e.g., two different colors) can be searched for at the same time in a top-down contingent manner (cf. Ansorge \& Horstmann, 2007; Irons, Folk, \& Remington, 2012). Research has also shown that if participants can search for two types of stimuli that would otherwise invite different templates (i.e., color-defined templates for red targets among white distractors; onset-directed templates for red onset targets) by only one template (in this case, for red targets), participants seemingly set up a single template allowing them to search for both of these target types at the same time. This is reflected in contingent-capture effects in such a situation - that is, validity effects of two types of different matching cues, red onset cues and red color cues, and successful ignorance of differently colored (blue) onset cues at the same time (see Experiment 5 of Goller et al., 2016). In the present experiment, our rationale was that an analogue principle during concomitant search for target words with a particular color meaning and hue-defined target rings of the same color as the meanings of the target words could amount to participants' setup of a semantic template for the particular color meaning if that would allow them searching for both of the two different target types.

However, the question if contingent-capture effects can be based on one search template for two very different types of stimuli (here, for hues and color words) is generally underresearched (but see Büsel, Pomper, \& Ansorge, 2018b; Irons et al., 2011), and the little existing evidence suggests that related kinds of top-down search for two features from different categories or dimensions (e.g., for a specific shape and a specific color) are not as efficient as search for two different features from the same category or dimension (i.e., for two different colors; Biderman, Biderman, Zivony, \& Lamy, 2017). Experiment 3, thus, also aimed to investigate this topic, but as it is more peripheral to the major questions of the present study, the corresponding results are delegated to Appendix F.

Importantly, as target types were presented unpredictably intermixed, at the time that a color-word cue was presented, participants did not yet know the type of the following target. Therefore, the color-word cues could have always captured attention and-following this line-could have elicited contingent-capture effects. The interesting question is, if under these conditions, in which the meaning or verbal content (e.g., its phonology) of the matching color-word cues could be taskrelevant and the processing of the matching color-word cues is ensured, we now find an interaction between contingent capture and target type that would be diagnostic of a different role of verbal or semantic templates during the processing of colorring targets versus the processing of color-word targets.

\section{Method}

Participants Twenty-two psychology students $\left(M_{\text {age }}=21\right.$ years, $S D_{\text {age }}=4.02$ years) of the University of Vienna participated in Experiment 3. Two students had to be excluded due to their error rates exceeding $20 \%$.

Procedure and design Participants searched for a specific color, which was equally likely implemented as a hue of a colorring target (as in Experiments 1a and 1b) or as the meaning of a color-word target (as in Experiment 2), and where the hue of 


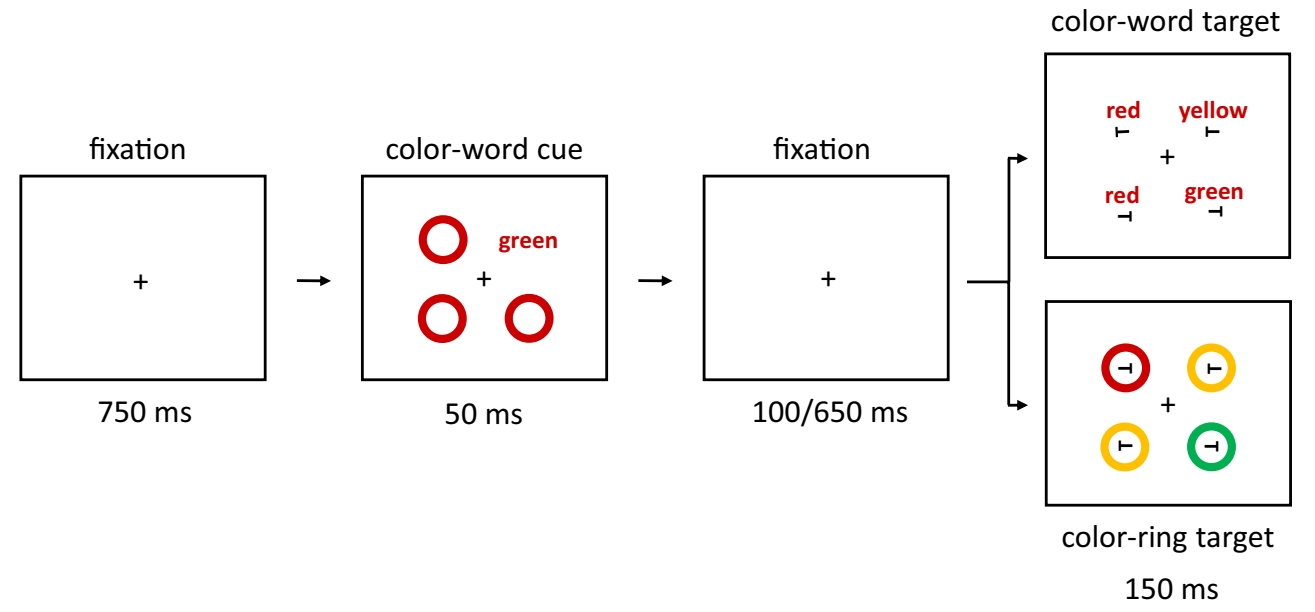

Fig. 10 Example trial(s) of Experiment 3. The target is the color word green in the upper rightmost box (color-word target) or the green color ring in the lower rightmost box. The color-word cue in this example is

the color-ring targets and the meaning of the color-word targets referred to the same color. As in Experiment 1a, the color-ring targets were blue or green nonsingleton rings (with target color balanced across participants) presented among one red and two yellow distractor rings or among two red and one yellow distractor ring. As in Experiment 2, the color-word targets were the words blue and green (with word identity balanced across participants, but corresponding to the color of the searched-for color-ring targets) presented among the distractor words yellow and red, and all of these words were presented in red or in yellow fonts (see Fig. 10). Both types of targets, color-ring targets and color-word targets, were presented equally likely and intermixed within the same blocks. All of the targets were preceded by color-word cues, with the same cueing displays as were used in Experiment 1a (and Experiment 2).

\section{Results}

\section{Reaction-time analysis}

Out of all trials, $13.64 \%$ were discarded from the RT analyses by the same criteria as were used in Experiments 1 and 2. This time, a repeated-measures ANOVA, with the variables target type (color-ring target, color-word target), validity (valid, invalid), cue match (matching, nonmatching), and SOA (150 $\mathrm{ms}, 700 \mathrm{~ms}$ ), led to a significant three-way interaction of Target Type $\times$ Validity $\times$ Cue Match, $F(1,19)=19.79, p<$ $.001, \eta_{\mathrm{p}}^{2}=.51$ (see Fig. 11). (Significant lower order interactions and main effects qualified by this significant highest order interaction of major interest can again be found in Table 2 in Appendix B; the exact mean correct RTs of all conditions are displayed in Table 8 in Appendix C.)

Post hoc $t$ tests, Bonferroni corrected for eight comparisons $($ alpha $=.006)$, examined validity effects and contingent capture for the different target types. matching and invalid. The arrows depict the flow of time. Stimuli are not drawn to scale. (Color figure online)

Color-ring targets The $t$ tests revealed a significant validity effect in color-ring target trials of both matching color-word cues (valid $\mathrm{RT}=575 \mathrm{~ms}$; invalid RT = $600 \mathrm{~ms}), t(19)=-6.16, p<.001, d=$ -1.34 , and nonmatching color-word cues (valid RT = $580 \mathrm{~ms}$; invalid RT $=595 \mathrm{~ms}), t(19)=-3.91, p=.001, d=-0.85$.

Color-word targets For word-target trials, we found the pattern corresponding to a classic contingent-capture effect: a validity effect of matching cues, $t(19)=-5.70, p<.001, d=-1.24$, and no validity effect of nonmatching cues, $t(19)=1.65, p=$ $.115, d=0.36$.

An additional analysis of task-switch costs can be found in Appendix F.

\section{Accuracy analysis}

Arcsine-transformed accuracy rates were analyzed by an ANOVA analogous to the first ANOVA of the RTs above. There was a significant three-way interaction of Target Type $\times$ Validity $\times$ Cue Match, $F(1,19)=7.89, p=.011, \eta_{\mathrm{p}}^{2}=.29$ (see Fig. 12). (See Table 3 in Appendix B for other significant main effects or interactions qualified by the three-way interaction, as well as Table 8 in Appendix $\mathrm{C}$ for an overview of the mean accuracy rates as a function of all factors.) Post hoc $t$ tests, Bonferroni corrected for eight comparisons (alpha = .006), were split up for target types.

Color-word targets and color-ring targets The post hoc tests yielded no significant validity effects for word-target trials, all $|t \mathrm{~s}|(19)<2.13$, all $p \mathrm{~s}=.046$, all $|d \mathrm{~s}|<0.47$, as well as no validity effects for color-ring target trials, all nonsignificant $|t \mathrm{~s}|(19)<1.45$, all $p \mathrm{~s}=.164$, all $|d \mathrm{~s}|<0.32$, but as is clear from Figs. 11 and 12, the results indicated the same pattern as in the RTs: numerically stronger validity-effect differences between matching and nonmatching color-word cues in color-word target trials than in color-ring target trials. 

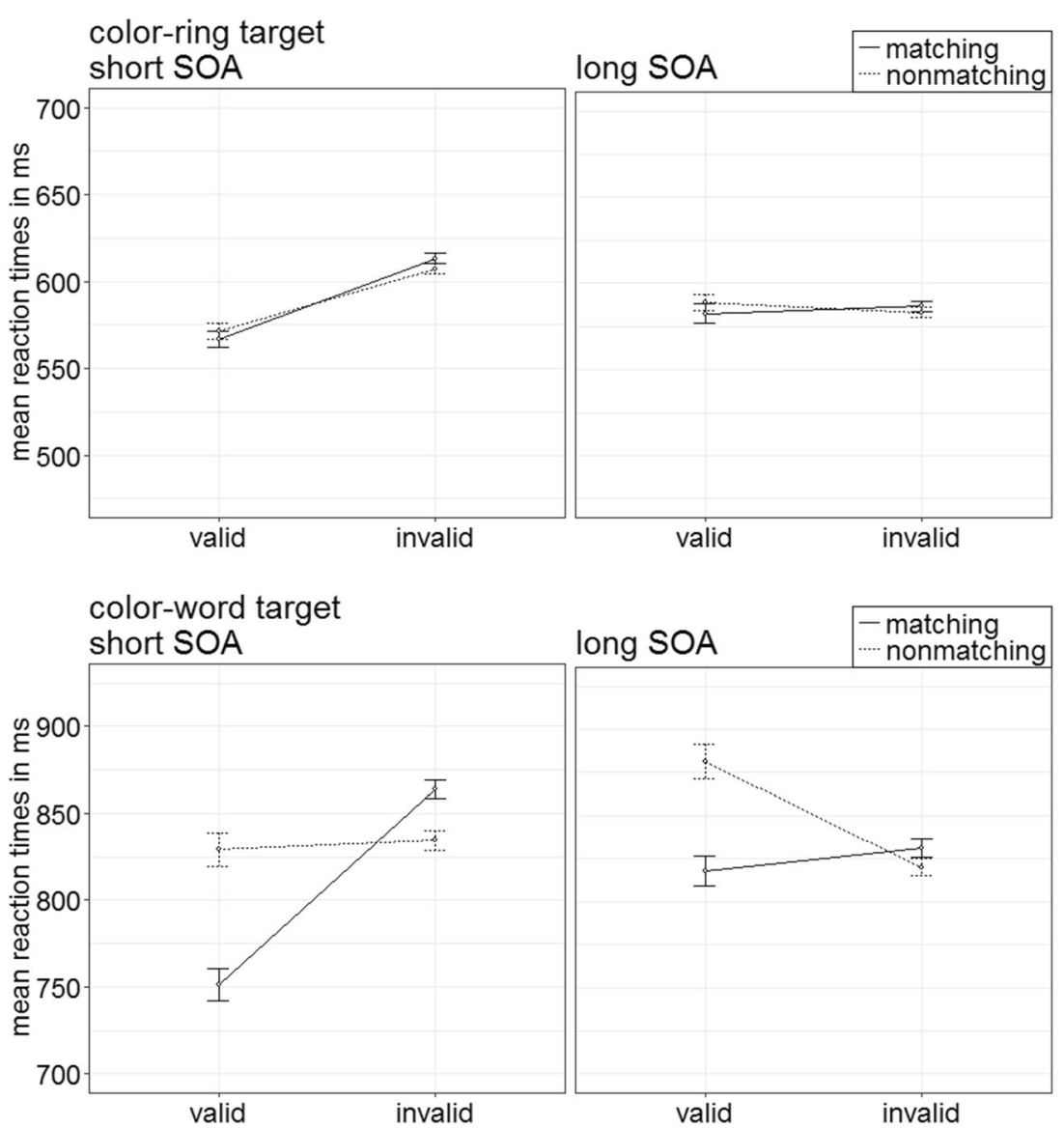

Fig. 11 Experiment 3: Mean correct reaction times (in $\mathrm{ms}$ ) for color-ring targets (upper panels) and color-word targets (lower panels) depending on stimulus-onset asynchrony (SOA), cue match, and validity. Error bars

represent average standard errors. Note the different ranges of reaction times in the graphs for color-ring and color-word targets

\section{Discussion}

As in Experiment 2, color-word cues preceding color-word targets led to what we referred to as contingent-capture effects: Only top-down matching color-word cues seemingly captured attention and accordingly facilitated search in valid as compared with invalid conditions, whereas the nonmatching color-word cues elicited no validity effect. In contrast, in color-ring target trials, both matching and nonmatching color-word cues led to a significant validity effect. Importantly, as in Experiments 1 and 2, these results suggest again that searching for and processing specific color-ring targets is not based on verbal or semantic templates, but, this time, the lacking contingent-capture effect based on colorword cue meaning in the color-ring target trials was even observed under conditions that were definitely sensitive to color-word cues, as was reflected in their validity effects in color-ring target trials and their selective validity effect with matching color-word cues in color-word trials.

Apart from our main question - if search templates for colors are semantically or feature based - the fact that a validity effect of all color-word cues was found for the color-ring targets, regardless of the match (vs. nonmatch) of their meanings to the target colors, also sheds a light on the potential origin of the difference between the validity effect of the matching color-word cues and the lack of a validity effect of the nonmatching color-word cues in the color-word target trials. The interested reader should refer to Appendix $F$ for a discussion of this topic.

Following Experiments 2 and 3, it is still open as to which mechanisms accounted for validity effects of matching color-word cues and the lacking validity effects of nonmatching color-word cues during word-target trials. It is possible that these differences between validity effects reflected word meaning. For example, if participants discriminated target words from distractor words by word meanings, it might have been more difficult to disengage attention from cues with a target-similar meaning. However, as each target word consisted of different letters or shapes for that matter and as even the same letter font was used for the matching cues as for the targets, it is possible that graphical shape representations accounted for the validity-effect difference. In addition, besides meaning, stronger validity effects of matching color- 

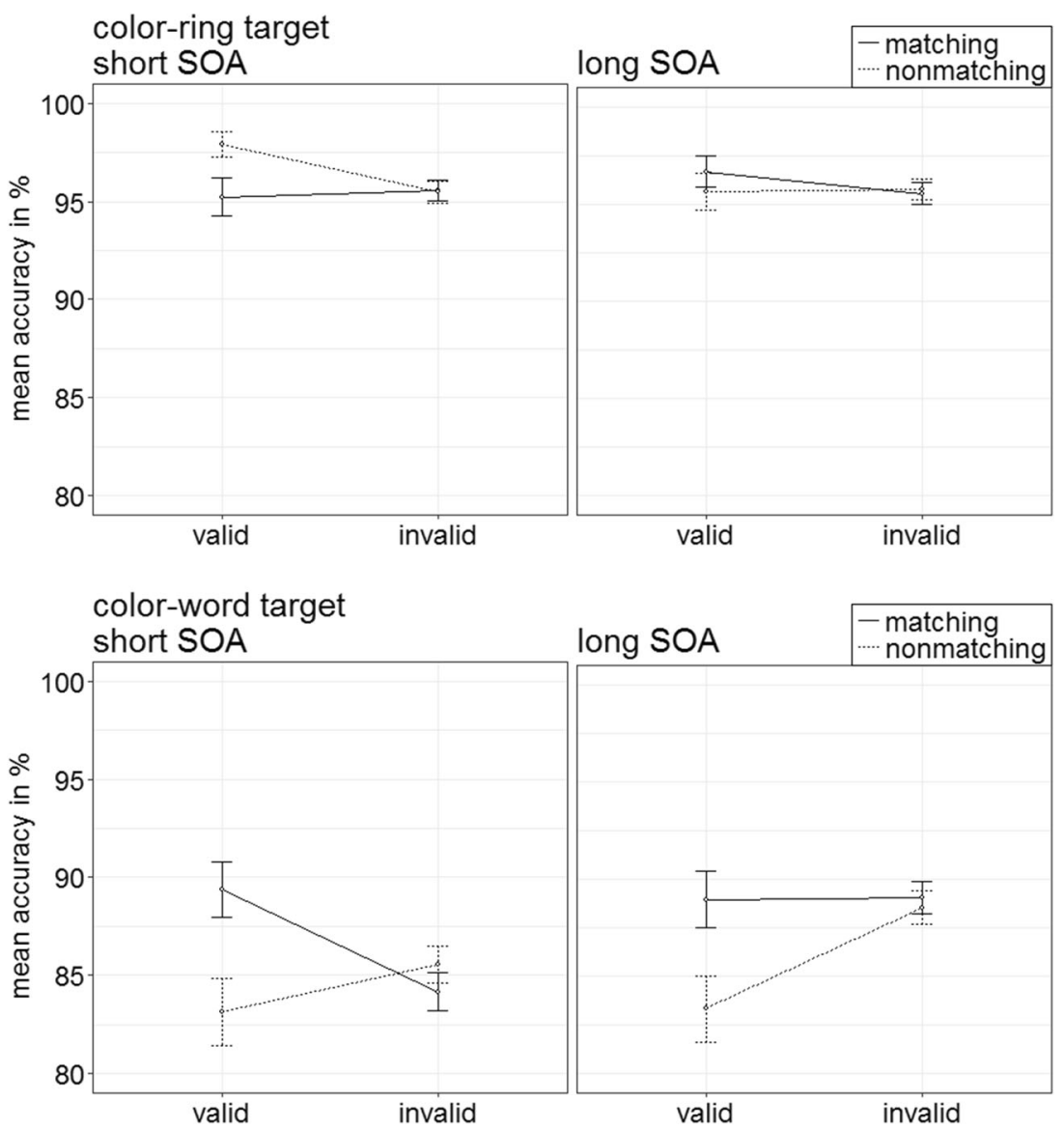

Fig. 12 Experiment 3: Mean accuracy rates in percentages for color-ring targets (upper panels) and color-word targets (lower panels) depending on stimulus-onset asynchrony (SOA), cue match, and validity. Error bars represent average standard errors

word cues than of nonmatching color-word cues might have also reflected their phonological representations. For example, more difficulties in disengaging from matching color-word cues might have been particularly likely if participants based their discrimination between target and distractor target-word representations held in working memory, as working memory representations are often of a phonological type (Baddeley, 1986; Baddeley, Lewis, \& Valar, 1984). Experiments 4 and 5 therefore investigated these questions more thoroughly.

\section{Experiment 4}

After Experiments 2 and 3, it is clear that matching colorword cues can lead to validity effects, but it is open which exact kind of mechanism was responsible for attention capture by matching cues and/or prolonged dwelling of attention at matching cues (see Appendix F for the latter possibility). So as not to suggest that only contingent capture based on search templates for specific words could account for the different validity effects of matching and nonmatching color-word cues, in the following, we used a more neutral terminology. ${ }^{2}$ For the rest of the present article, we speak of "target-distractor discrimination" to make clear that the processes responsible for validity effects of matching color-word cues and lacking or inverted cueing effects of nonmatching color-word cues might be preselective or postselective (defined as relative to the selection of any words).

Importantly, the discrimination between color-word targets and color-word distractors could be based on different characteristics, such as semantic, phonological, orthographical, or graphical information. Experiment 4 was the first of two experiments aimed at investigating the particular mechanisms that were involved in the discrimination between the color words and, by implication, in the robustness of the validityeffect differences between matching and nonmatching color-

\footnotetext{
${ }^{2}$ To note, however, a number of results confirmed that the contingent-capture account holds true for color cues. For example, when using the $\mathrm{N} 2 \mathrm{pc}$ - an event-related potential record of attention capture with millisecond precision that allows to study capture directly after the cues before the overt responsesone can see that the matching cue captures attention initially, directly after its onset, more reliably than the nonmatching cue, thus ruling out a deallocation explanation, which assumes initially equal capture by all cues but faster disengagement of attention following nonmatching than matching cues (Ansorge et al., 2011; Eimer \& Kiss, 2008).
} 
word cues. Due to the short presentation time of the colorword cues $(50 \mathrm{~ms})$ and the lack of evidence for semantic effects in Experiments 1-3, it is possible that participants did not read the color words but rather identified some specific graphical features to discriminate targets from distractors, like the shape of some of the letters of the targets. In Experiment 4, we tested if discrimination between color-word targets and color-word distractors could be based on graphical features by presenting color-word cues in target-similar or targetdissimilar fonts (see Fig. 13). If participants use the graphical features of the target words to tell target and distractors apart, only cues with the same graphical features as the target should capture attention and/or be difficult to ignore (and, thus, prevent rapid disengagement), and lead to validity effects. If graphical features are not used to tell targets from distractors, all matching word cues (e.g., with the same meaning and phonology as the target) could capture attention, independent of their graphical similarity to the target.

\section{Method}

Participants Twenty participants took part in Experiment 4 $\left(M_{\text {age }}=23.55\right.$ years, $S D_{\text {age }}=5.16$ years $)$.

Procedure and design Methods were as in Experiment 2. In each trial, participants searched for a specific color word (green or blue, balanced across participants). However different from Experiment 2, the target display was equally likely and unpredictably preceded by either a color-word cue with a target-similar font (i.e., both target and cue were written in lowercase letters) or with a target-dissimilar font (i.e., the cue was in uppercase and the target in lowercase letters; see Fig. 13). (Color cue conditions were not realized.)

\section{Results}

Reaction-time analysis As in the first three experiments, trials with false responses were removed, as well as responses faster or slower than two standard deviations from the median per person and per condition (in total, $18.40 \%$ ). A $2 \times 2 \times 2 \times 2$, repeated-measures ANOVA, with the factors cue type (colorword cue font similar to target, dissimilar to target), validity (valid, invalid), cue match (matching, nonmatching), and SOA (150 ms, $700 \mathrm{~ms})$, was conducted. As its highest order significant interaction of major interest, it showed a two-way interaction of Validity $\times$ Cue Match, $F(1,19)=88.10, p<$ $.001, \eta_{\mathrm{p}}^{2}=.82$ (see Fig. 14). (See also Table 2 in Appendix B for other significant main effects, and Table 9 in Appendix C for all mean RTs of Experiment 4.)

Post hoc $t$ tests, Bonferroni corrected for four comparisons $($ alpha $=.013)$, revealed a validity effect for matching cues (valid RT $=770 \mathrm{~ms}$; invalid $\mathrm{RT}=836 \mathrm{~ms}$ ), $t(19)=-5.26, p$ $<.001, d=-1.15$, and no significant effect for nonmatching cues (valid RT $=855 \mathrm{~ms}$; invalid RT $=812 \mathrm{~ms}$ ), $t(19)=1.30, p$ $=.208, d=0.28$.

Accuracy analysis As before, accuracy rates were arcsine transformed for an ANOVA as the one above. It also showed a significant two-way interaction of Validity $x$ Cue Match, $F(1,19)=55.64, p<.001, \eta_{\mathrm{p}}^{2}=.75$ (see Fig. 15). (For other significant effects, refer to Table 3 in Appendix B; for all mean accuracy rates of Experiment 4, see Table 9 in Appendix C.)

Post hoc $t$ tests with an alpha of .013 (Bonferroni corrected for four comparisons) yielded no significant validity effect for matching cues (valid accuracy rate $=88.8 \%$; invalid accuracy rate $=86.7 \%), t(19)=2.09, p=.050, d=0.46$. However, on average, reactions with nonmatching cues were significantly

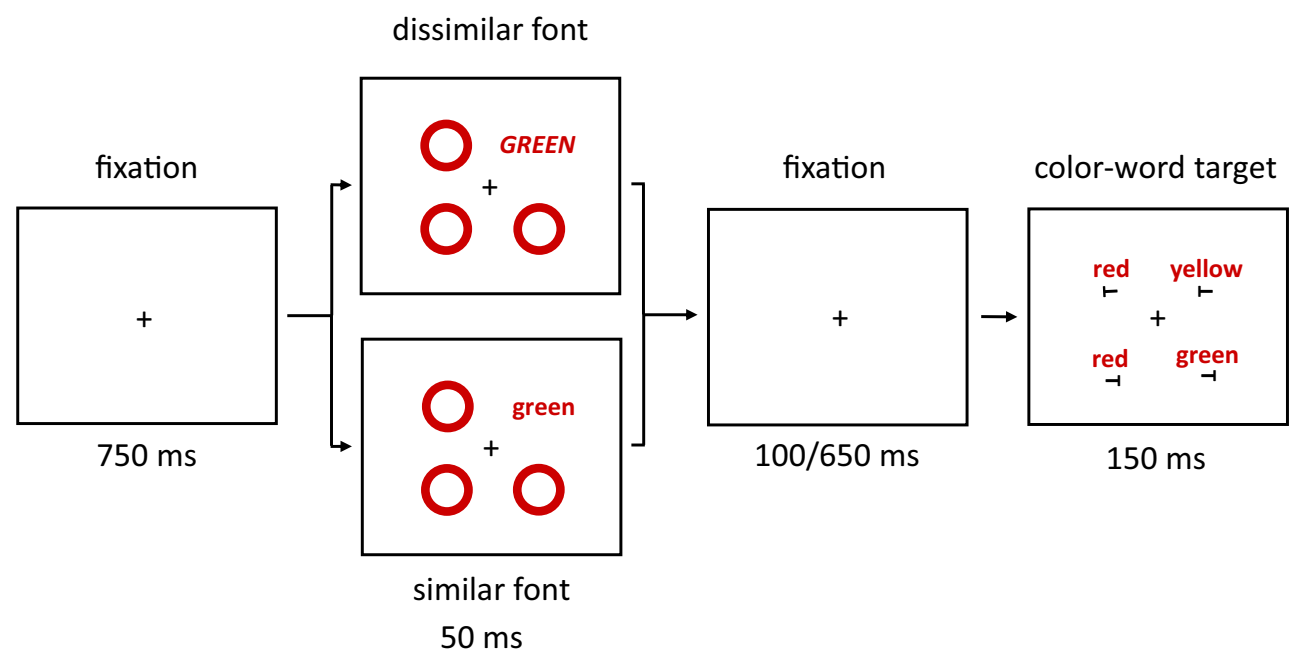

Fig. 13 Exemplary trial(s) of Experiment 4. The target is the color word green in the rightmost box (the target word remained either green or blue, varied between participants, throughout the whole experiment). Two different cue versions are displayed in the boxes second from left (both

invalid and matching): a color-word cue written in target-dissimilar font (top); a color-word cue written in target-similar font (bottom). The arrows depict the flow of time. Stimuli are not drawn to scale. (Color figure online) 

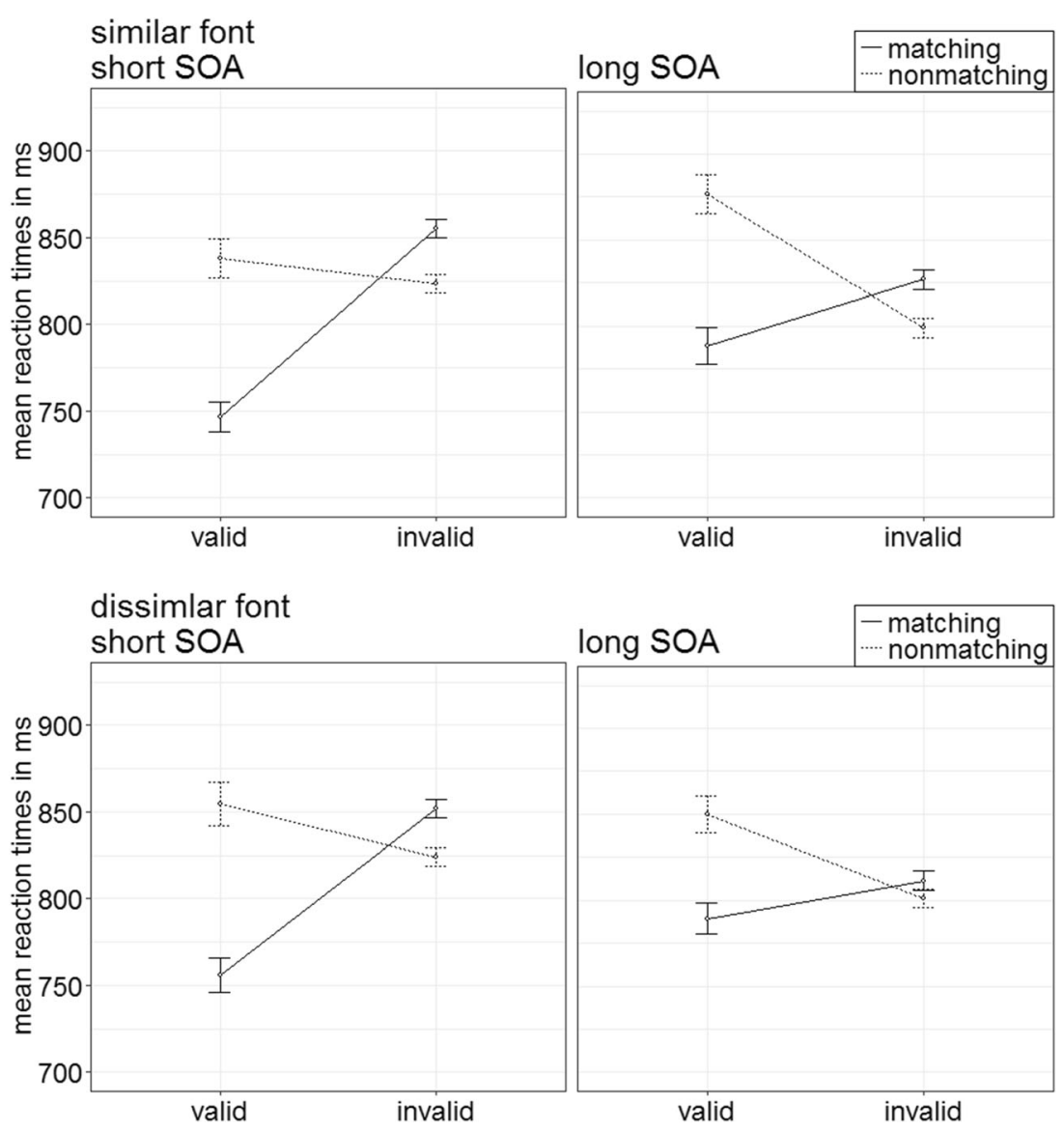

Fig. 14 Experiment 4: Mean correct reaction times (in ms) for color-word cues with a font similar to the target (upper panels) and dissimilar to the target (lower panels) depending on stimulus-onset asynchrony (SOA), cue match, and validity. Error bars represent average standard errors

more accurate in invalid $(87.4 \%)$ than in valid $(81.8 \%)$ conditions, $t(19)=-4.67, p<.001, d=-1.02$.

\section{Discussion}

In Experiment 4, validity effects were not influenced by the similarity between the font of the cue and that of the target. If the color-word cues were of the same meaning and phonology as the color-word targets, in valid conditions, both cue versions led to faster RTs than target-dissimilar cue words of a different meaning and phonology than the targets, and in invalid conditions, both more target-similar versions led to slower RTs than did more target-dissimilar cues. More target-dissimilar cues (with dissimilarity in terms of their meaning and phonology) of both font-similarity levels did not significantly influence RTs.

Slightly different effects arose in the accuracy rates: More target-similar cues did not lead to any significant effects, whereas for more target-dissimilar cues, performance was impaired in valid conditions compared with invalid conditions. This result corresponded to a same-location cost.

The difference of the validity effects suggested that colorword cues captured and/or held attention independently of their graphical similarity to the target words, falsifying the notion that target-distractor discrimination between color words was based on graphical features.

\section{Experiment 5}

Experiment 5 was the second test of the mechanism of the discrimination between color-word targets and color-word distractors. Walenchok et al. (2016) found that phonological distractors sounding similar to searched for target objects delayed target search under some conditions, in which participants might have used phonologically defined search templates maintained in the phonological loop of working memory (cf. Baddeley, 1986). To examine the role of phonological representations as templates to discriminate between target-color and distractor-color words, in Experiment 5, participants again searched for a color-word target preceded by a color-word cue, but, additionally, in only one of two blocks we included an articulatory suppression task. This articulatory suppression task should interfere with rehearsal and processing via the phonological loop (Baddeley et al., 1984). 

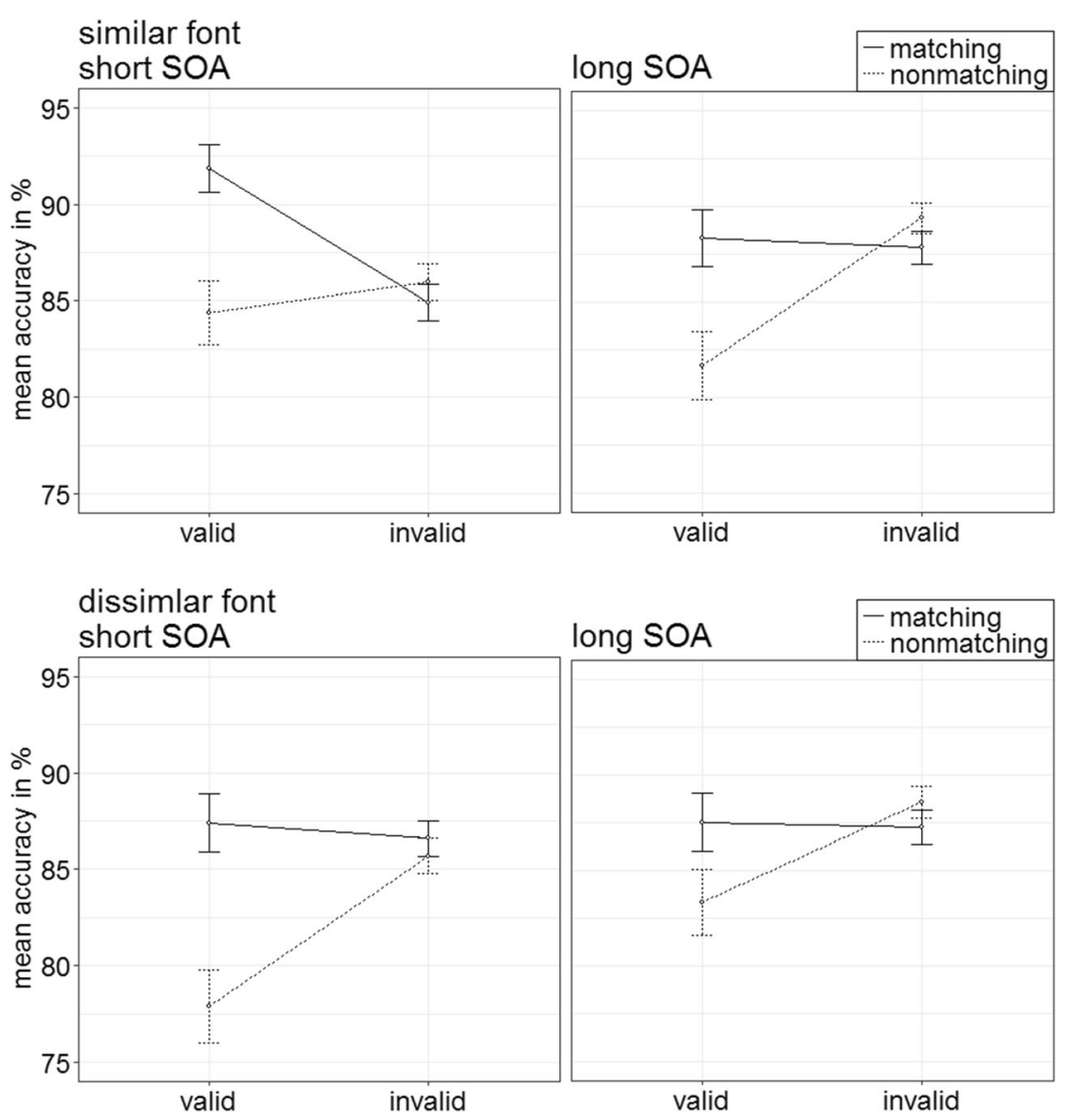

Fig. 15 Experiment 4: Mean accuracy rates in percentages for color-word cues with a font similar to the target (upper panels) and dissimilar to the target (lower panels) depending on stimulus-onset asynchrony (SOA), cue match, and validity. Error bars represent average standard errors

If discrimination between color words relies at least partly on phonological information held in working memory (Walenchok et al., 2016), validity effects of matching colorword cues should have been impaired when participants performed an additional articulatory suppression task. To equate attentional dual-task demands between blocks with articulatory suppression and control blocks without articulatory suppression, an additional secondary task that does not interfere with phonological processing was included in the control block: foot tapping (cf. Weywadt \& Butler, 2013). Whatever the results in the phonological suppression task, in the control block, with the foot tapping as a secondary task, we expected to replicate validity effects of target-similar color-word cues and no validity effects of target-dissimilar color-word cues, as in Experiments 2 and 4, and in the color-word target conditions of Experiment 3.

\section{Method}

Participants Twenty-one students of the University of Vienna participated in Experiment $5\left(M_{\text {age }}=21.71\right.$ years, $S D_{\text {age }}=2.76$ years). Three had to be excluded due to a high error rate $(>20 \%)$.
Procedure and design Methods were similar to those in Experiment 2. Participants searched for a predefined colorword target. However, a color-word cue preceded each target, and the experiment was divided into two blocks, with block order counterbalanced across participants. In the articulatory suppression block, participants searched for the target words, and their additional task was to repeat the syllable "fi" continuously to the beat of a metronome $(60 \mathrm{bpm})$. In the control block, participants also had to search for color-word targets, but additionally they had to continuously tap with one foot, again to the beat of a metronome $(60 \mathrm{bpm})$. This procedure was created following Saeki and Saito (2004). To ensure that the additional tasks were performed as instructed, audio files of speaking and tapping performance were recorded and checked for performance accuracy.

\section{Results}

Reaction-time analysis Trials were eliminated by the same criteria as in the preceding experiments (in total, 16.12\%). A $2 \times 2 \times 2 \times 2$ repeated-measures ANOVA, with the variables block (visual search + foot tapping, visual search + syllable repetition), validity (valid, invalid), cue match (matching, 
nonmatching), and SOA (150 ms, $700 \mathrm{~ms})$, demonstrated a significant two-way interaction of Validity $\times$ Cue Match, $F(1$, 17) $=68.84, p<.001, \eta_{\mathrm{p}}^{2}=.80$ (see Fig. 16; Table 10 in Appendix C). (See Table 2 in Appendix B for further significant results.)

Post hoc $t$ tests examining contingent-capture and validity effects with an alpha of .013 (Bonferroni corrected for four comparisons) revealed a significant validity effect for matching cues, $t(17)=-6.48, p<.001, d=-1.49$, and a significantly inverted validity effect for nonmatching cues, $t(17)=3.32, p=.004, d=0.76$.

Accuracy analysis Arcsine-transformed accuracy rates were submitted to an analogous ANOVA. It showed a significant two-way interaction of the variables Validity $\times$ Match, $F(1$, 17) $=14.10, p=.002, \eta_{\mathrm{p}}^{2}=.45$ (see Fig. 17; Table 10 in Appendix C). (See Table 3 in Appendix B for further significant effects.)

Post hoc $t$ tests, Bonferroni corrected for four comparisons $($ alpha $=.013)$, yielded no significant validity effect for matching cues, $t(17)=2.34, p=.032, d=0.54$. However, on average, the reactions for nonmatching cues were significantly more accurate in invalid $(89.5 \%)$ than in valid $(85.0 \%)$ conditions, $t(17)=-2.95, p=.009, d=-0.68$.

\section{Discussion}

Altogether, the results of Experiment 5 show validity effects by matching color-word cues, with weak same-location costs by nonmatching color-word cues. These effects were not affected by the articulatory suppression task at all. This is evidence against a target-distractor discrimination based on phonological features held in working memory. If discrimination would have relied at least partly on target-word rehearsal in the phonological loop, the articulatory suppression task should have interfered with the validity effect of the matching color-word cues. As this was not the case, it is more likely that representations for target-distractor discrimination were held in long-term memory or included other target-defining characteristics, such as orthographic features or, less likely, word meanings. To note, as the target was the same throughout the experiment, it is possible that participants used a long-term memory representation to discriminate between target and distractor words.
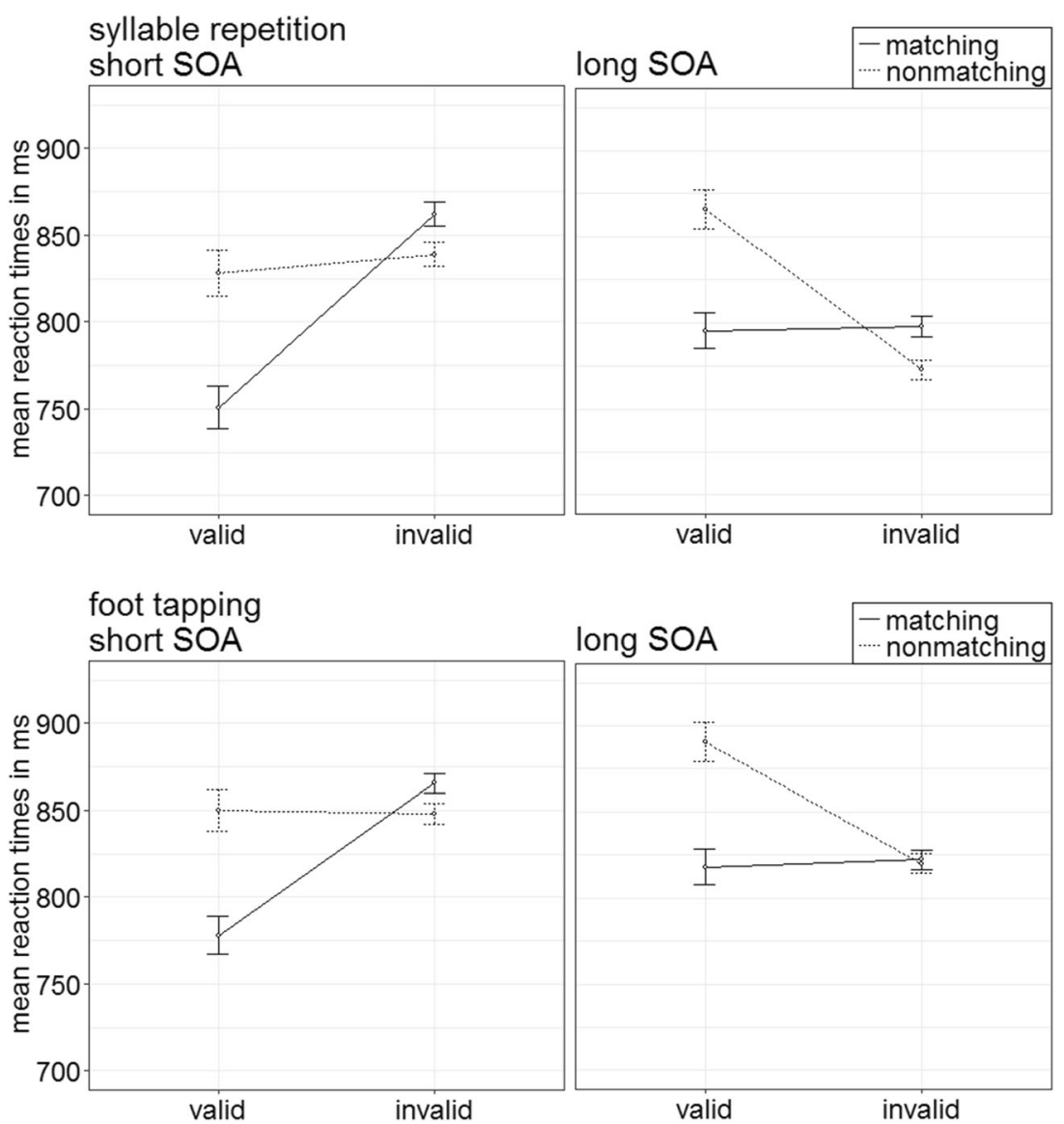

Fig. 16 Experiment 5: Mean correct reaction times (in $\mathrm{ms}$ ) for visual search plus syllable repetition (i.e., articulatory suppression task; upper panels) and visual search plus foot tapping (i.e., control task; lower

panels) depending on stimulus-onset asynchrony (SOA), cue match, and validity. Error bars represent average standard errors 

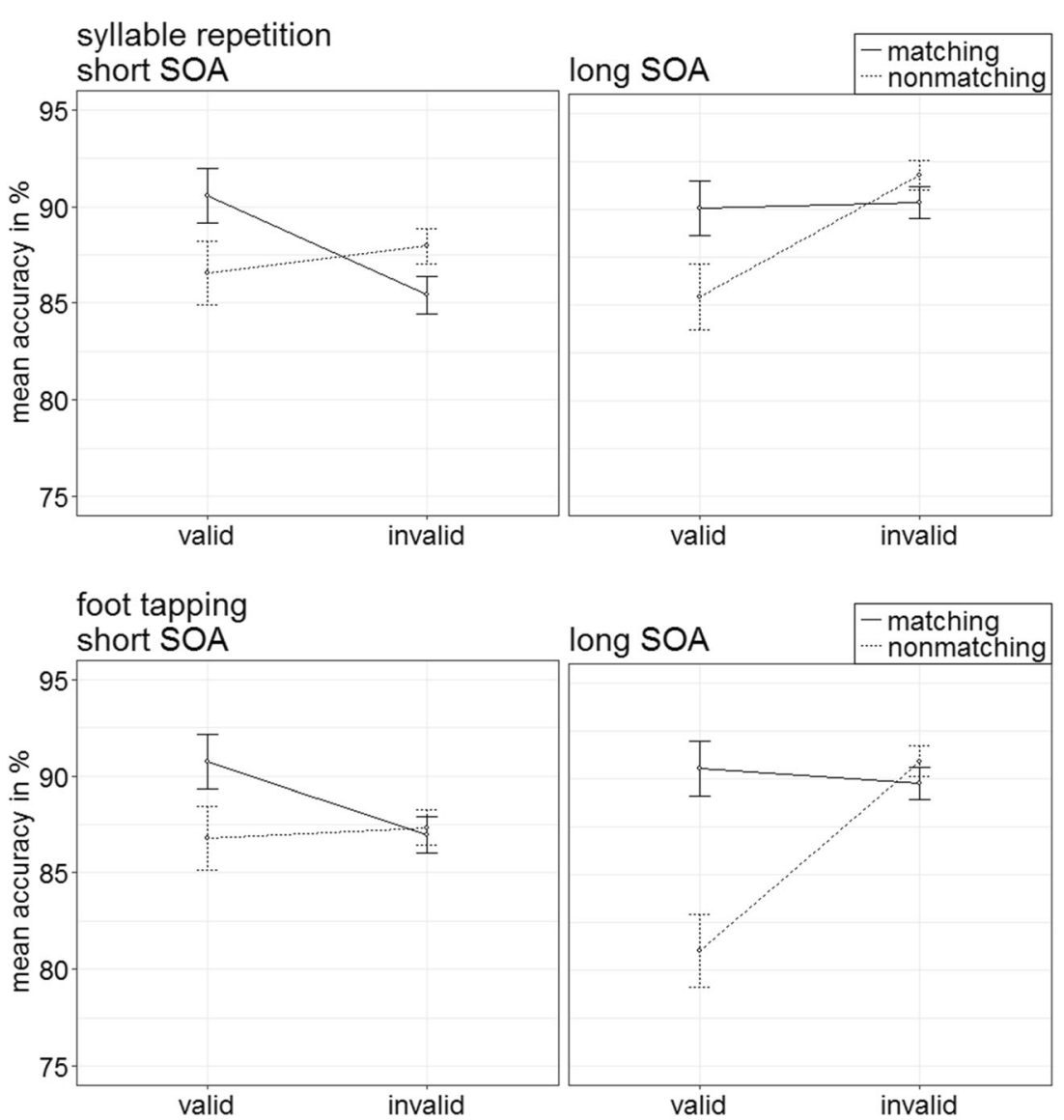

Fig. 17 Experiment 5: Mean accuracy rates in percentages for visual search plus syllable repetition (i.e., articulatory suppression task; upper panels) and visual search plus foot tapping (i.e., control task; lower

panels) depending on stimulus-onset asynchrony (SOA), cue match, and validity. Error bars represent average standard errors

\section{General Discussion}

\section{Contingent capture by color: No evidence for verbal and semantic templates}

In a series of five experiments, we examined if top-down search could be based on verbal or semantic templates (for an overview, see Table 1). Different types of top-down search templates have been discussed in the visual search literature: templates consisting of visual features (e.g., Jenkins et al., 2017), verbal representations (e.g., Walenchok et al., 2016), or semantic characteristics (e.g., Belke et al., 2008). Using color-word cues, our results showed no evidence of contributions by verbal or semantic templates during search for color targets. In Experiment 1a, searching for a color-ring target, color-ring cues but not color-word cues led to contingentcapture effects. In fact, color-word cues had no significant validity effect at all. In Experiment 1b, color-word cues were replaced by parafoveally presented symbolic cues, each associated with a different specific color. As in Experiment 1a, only color-ring cues led to contingent-capture effects. Symbolic cues only produced an inversed validity effect in

matching trials that could, however, be of a different origin (e.g., inhibition of the symbols because they otherwise elicited color representations at variance with $50 \%$ of the following targets). In Experiment 2, searching for color-word targets, matching but not nonmatching color-word cues led to validity effects, but now color-ring cues only created a small contingent-capture effect in the error rates. ${ }^{1}$ The lacking contingent-capture effect of the color-ring cues in the RTs showed again that capture by color-ring stimuli was mostly unrelated to word-directed (e.g., verbal or semantic) search templates. Finally, in Experiment 3, participants searched for both color-ring targets and color-word targets while only color-word cues were used. In this experiment, we studied the involvement of verbal or semantic templates during color search in the contingent-capture experiment, not by the contingent-capture effect of the color-ring or color-word cues themselves, but rather more indirectly by the interaction of cue type with the type of target. In this situation, the validity effect of the matching color-word cues was restricted to the colorword target trials. In contrast, in the color-ring target trials, both matching and nonmatching color-word cues showed a small validity effect. The latter was different from 
Experiment 1a. Again, however, the results were at odds with a verbal or semantic template during search for color targets, as this should have led to more capture by matching colorword cues than nonmatching color-word cues during search for color-ring targets, too.

Together, the results of Experiments 1a and 3 also suggested that the validity effect of color-word cues was absent where color words were irrelevant (in Experiment 1a) and that it was present where color words were relevant. This means that the validity effect of the color-word cues in the color-ring target trials of Experiment 3 reflected a form of contingent capture, too. However, this was a contingent-capture effect based on a search template for just any (color) word or (some of) its constituents (e.g., letters).

\section{Relation to the Stroop effect}

Some of the results of Experiments 1a, 2, and 3 might appear surprising in light of Stroop effects and evidence for the automatic processing of color words during color discrimination tasks (MacLeod, 1991; MacLeod \& McDonald, 2000; Stroop, 1935). For instance, responses are typically faster to print colors of color words with a color-congruent meaning than with a colorincongruent meaning, and such Stroop effects can also be observed where there is an interval between color word and color stimulus (e.g., Dyer \& Severance, 1973; Weekes \& Zaidel, 1996) and where color word and color stimulus are not presented at the same location (e.g., Dyer, 1973; Gatti \& Egeth, 1978; Kahneman \& Chaiczyk, 1983). Hence, some of the critical side conditions for a Stroop effect were fulfilled in the present experiments, and this raises the question as to why no influence of word identities or of the interaction between word identities and spatial word-tocolor-ring target distance on color-ring target processing was found in these experiments.

One decisive difference between the present study and past research is that, typically, the Stroop effect is measured where stimulus color needs to be discriminated by different overt responses. Response interference between incompatible colorword meaning and target colors therefore contributes to the standard Stroop effect (Durgin, 2000; Klein, 1964). However, no overt responses directly discriminated between target colors in the current study. Instead, the current study used a compound search task in which color was necessary to locate the target, but the overt responses discriminated a different attribute of the same targets - here, the orientation of a $T$ at color-ring target location. In addition, the Stroop effect diminishes for task-peripheral and to-be-suppressed distractors (Wuehr \& Frings, 2008), and, arguably, our participants suppressed all of the uninformative cues of the present study, only with different success (i.e., less success with top-down matching cues) (Fuchs et al., 2013; Gaspelin, Ruthruff, \& Lien, 2016). These factors might have prevented any strong Stroop effects in the present study.

\section{Mechanisms involved in the discrimination of color words}

In the final two experiments, we also studied how target and distractor words were discriminated so that more evidence for capture and/or dwelling of attention could be found with matching than with nonmatching color-word cues. Several possibilities of how participants could have discriminated between the parafoveally presented visual color words are conceivable, such as a discrimination between graphical features of the (target vs. distractor) color words, between phonological features of these words, or even between their semantic features. As some of these variants would not even have required reading of the words but could have rather invited shape-based search, we tested some of these possibilities. For example, past studies have shown that parafoveally presented stimuli that are graphically similar to the target word facilitate target word processing (Rayner, McConkie, \& Zola, 1980; Slattery, Angele, \& Rayner, 2011; see also Paap, Newsome, \& Noel, 1984). This implies that discrimination based on the graphical features of the parafoveally presented target words and, therefore, the matching and nonmatching color-word cues was a possibility, so we put this to a test in Experiment 4. Here, we tested if target-color words could be discriminated based on graphical features, but whether a target-similar or target-dissimilar font was used for the colorword cues had no impact on the validity effect of the matching color-word cues. However, this finding does not preclude the possibility that the participants could have used some sort of orthographical template, as even parafoveally presented stimuli that were not identical with the target and only graphically similar to the target have been shown to facilitate target word processing (Rayner et al., 1980; Slattery et al., 2011; see also Paap et al., 1984).

In addition, phonological target-word representations could have likewise allowed discriminating between target and distractor words and, hence, also between matching and nonmatching color-word cues (cf. Baddeley, 1986; Walenchok et al., 2016). In Experiment 5, we tested if color-word discrimination could be based on subvocal rehearsal, but whether we used a secondary articulatory suppression task or a secondary tapping control task had no influence on the validity effect of the matching color-word cues. This does preclude that a phonological working memory representation was responsible for the validity effect of the matching color-word cues. However, such discrimination based on phonological target-word characteristics could be based on long-term memory (cf. Coltheart, Curtis, Atkins, \& Haller, 1993). In line with the possibility that participants phonologically discriminated between target and distractor words of the current Experiments 2-5, some prior studies demonstrated phonological priming by parafoveally presented words in a preview advantage of target-word recognition (e.g., Pollatsek, Lesch, Morris, \& Rayner, 1992). In addition, as the 
target words were kept the same for each participant throughout Experiments 2-5, favorable conditions for templates based on long-term memory could have been met in the current study (Carlisle et al., 2011; see also Grubert, Carlisle, \& Eimer, 2016). Thus, phonological long-term memory templates could have possibly been responsible for stronger validity effects following matching than nonmatching color-word cues during search for color-word targets.

In theory, it is even possible that participants used a semantic representation to discriminate between target and distractor words. In line with this possibility, in German, as was used here, semantic facilitation by parafoveally presented words is a robust effect (Hohenstein \& Kliegl, 2014; Hohenstein, Laubrock, \& Kliegl, 2010). Now, seemingly, Experiments 2 and 3 did not support a semantic discrimination. Otherwise, we should have found more evidence of a contingent-capture effect of color-ring cues during search for color-word targets and of color-word cues during search for color-ring targets because interactions between sensory stimuli and words are typical, if not even defining, characteristics for a semantic effect (cf. Glaser \& Glaser, 1989; McCauley, Parmelee, Sperber, \& Carr, 1980; Schmidt \& Zelinsky, 2009). However, it is possible that more evidence of a semantic discrimination during search for color-word (and even colorring) targets could be found if stimuli less complex than words or outline sketches of objects semantically associated to colors (e.g., of hearts for red or stars for yellow stimuli; see Experiment 1b) would be used as cues. For example, one could try to use spoken words as auditory cues in future experiments (cf. Lupyan \& Spivey, 2010). Maybe semantics of spoken words are easier to process and, thus, able to tap into the semantic nature of color-directed search templates.

\section{Relation to categorical search}

In the current study, the lack of contingent-capture effects by color-word cues during search for color-ring targets could have been due to some form of category-search template constraining the overall range of stimuli that could capture attention (cf. Wyble, Folk, \& Potter, 2013; Yang \& Zelinsky, 2009). For example, searching for a color-ring target, it might be difficult to successfully ignore other stimuli partly matching the target category, such as other rings. Yet it could be that stimuli of a sufficiently different category, such as words or shapes that are not rings, would never capture attention in this situation. If this was the case, our results would be suggestive that category-based capture effects (i.e., capture by objects similar to the target category rather than to specific target features) are not brought about by a category's semantics. If the latter were true, again, we would have expected capture by color-word cues during search for color-ring targets, as cross-modal processing (here, across visual and verbal modes) is one hallmark of a semantic effect (e.g., Glaser \& Glaser, 1989). However, what we said above applies here, too, and future tests could use simpler stimuli than visual words or than outline sketches semantically associated to particular colors, to once more put to test the possibility that search for color targets is based on target semantics.

\section{Conclusion}

Altogether, our results are best in line with hue-based contingent-capture effects. As participants treated color-ring cues and color-ring targets, on the one hand, and color-word cues and color-word targets, on the other hand, as largely separate events (see also Appendix F, switch costs of Experiment 3) and as only color-ring cues elicited clear contingent-capture effects when the targets were out of the same stimulus category (namely, also colored rings), verbal or semantic templates during search for color in contingent-capture experiments were not supported by the present findings. In addition, which types of discrimination between relevant and irrelevant words accounted for stronger validity effects by matching than nonmatching word cues in color-word target trials requires additional research in the future, but semantic and phonological working memory templates are unlikely candidates for color-word based contingent-capture effects.

This, however, does not mean that we would have generally falsified the use of semantic templates in visual search. Factors, such as how well an irrelevant cue can be filtered out by a huebased template, could have fostered participants' use of a huebased rather than a semantic template in some conditions (e.g., the present contingent-capture Experiments 1a and 1b). Thus, we can only conclude that contingent capture by uninformative color cues is likely not based on semantic search templates.

\section{Open practices statement}

None of the data or stimuli material of Experiments $1 \mathrm{a}-5$ are available online; however, we will gladly provide them if requested. The experiments were not preregistered.

Author note This research was supported by WWTF grant (CS15-001) awarded to Soonja Choi and Ulrich Ansorge (University of Vienna).

Acknowledgements Open access funding provided by University of Vienna. 


\section{Appendix A}

Detailed description of the differences in the results between a two standard deviation and three standard deviation cutoff value in the preprocessing of the RTs

Together with the removal of trials with wrong responses, a three standard deviation cutoff value leads to a total removal of $6.63 \%$ (Experiment 1a), 9.17\% (Experiment 1b), 8.13\% (Experiment 1b, congruency test), 9.66\% (Experiment 2), 9.79\% (Experiment 3), $14.62 \%$ (Experiment 4), and $12.57 \%$ (Experiment 5) of the data. The pattern of results remains the same, except for the following differences.

Experiment 1a: In the post hoc $t$ tests after the significant four-way interaction in the ANOVA, the validity effect of matching word cues in the short SOA becomes significant, whereas the validity effect of matching color cues in the long SOA is no longer significant.

Experiment 1b: An additional two-way interaction in the ANOVA is significant, SOA $\times$ Validity. In the post hoc $t$ tests justified by the significant three-way interaction, the validity effect of matching symbolic cues in the short SOA is no longer significant.

Experiment 3: In the ANOVA, the main effect of validity as well as the Target Type $\times$ SOA interaction are no longer significant. In the post hoc $t$ tests examining the significant threeway interaction, the difference between matching and nonmatching invalid color targets becomes significant, whereas the same-location costs with nonmatching color targets, as well as the difference between matching and nonmatching invalid color-word target conditions, are no longer significant. In the additional analysis examining task-switch costs, the three-way interaction Target Type $\times$ Validity $\times$ Target Type in Trial $N-1$ is significant. The post hoc $t$ test examining the difference between target type and target type in trial $n-1$ showed significant task-switch costs in all conditions, except for invalid target words.

Experiment 4: In the post hoc $t$ tests, the same-location costs of nonmatching cues are now significant.

\section{Appendix B}

Detailed listing of all significant results of ANOVAs of mean correct reaction times and accuracy rates of Experiments 1a-5

Table 2 All significant main effects and interactions of the conducted analyses of variance with mean correct reaction times of Experiments 1a-5

\begin{tabular}{|c|c|c|c|c|}
\hline Significant main effects and interactions & $d f$ & $F$ & $p$ & $\eta_{p}^{2}$ \\
\hline \multicolumn{5}{|l|}{ Experiment 1a } \\
\hline Cue Type & 20 & 7.56 & .012 & .27 \\
\hline Validity & 20 & 15.67 & $<.001$ & .44 \\
\hline Cue Type $\times$ SOA & 20 & 10.24 & .004 & .34 \\
\hline Cue Type $\times$ Validity & 20 & 139.60 & $<.001$ & .87 \\
\hline Validity $\times$ Cue Match & 20 & 39.71 & $<.001$ & .67 \\
\hline Cue Type $\times$ SOA $\times$ Validity & 20 & 13.40 & .002 & .40 \\
\hline Cue Type $\times$ SOA $\times$ Cue Match & 20 & 14.17 & .001 & .41 \\
\hline Cue Type $\times$ Validity $\times$ Cue Match & 20 & 53.15 & $<.001$ & .73 \\
\hline Cue Type $\times$ SOA $\times$ Validity $\times$ Cue Match & 20 & 17.75 & $<.001$ & .47 \\
\hline \multicolumn{5}{|l|}{ Experiment $1 \mathrm{~b}$} \\
\hline Validity & 19 & 12.99 & .002 & .41 \\
\hline Cue Type $\times$ Validity & 19 & 78.27 & $<.001$ & .80 \\
\hline Validity $\times$ Cue Match & 19 & 65.23 & $<.001$ & .77 \\
\hline Cue Type $\times$ SOA $\times$ Validity & 19 & 13.47 & .002 & .41 \\
\hline Cue Type $\times$ SOA $\times$ Cue Match & 19 & 7.28 & .014 & .28 \\
\hline Cue Type $\times$ Validity $\times$ Cue Match & 19 & 47.01 & .001 & .71 \\
\hline SOA $\times$ Validity $\times$ Cue Match & 19 & 9.00 & .007 & .32 \\
\hline Cue Type $\times$ SOA $\times$ Validity $\times$ Cue Match & 19 & 10.15 & .005 & .35 \\
\hline
\end{tabular}


Table 2 (continued)

\begin{tabular}{|c|c|c|c|c|}
\hline Significant main effects and interactions & $d f$ & $F$ & $p$ & $\eta_{p}^{2}$ \\
\hline \multicolumn{5}{|l|}{ Experiment 2} \\
\hline Cue Type & 17 & 5.41 & .033 & .24 \\
\hline Cue Match & 17 & 36.84 & $<.001$ & .68 \\
\hline SOA $\times$ Validity & 17 & 37.25 & $<.001$ & .69 \\
\hline Cue Type $\times$ Cue Match & 17 & 14.45 & .001 & .46 \\
\hline Validity $\times$ Cue Match & 17 & 52.23 & $<.001$ & .75 \\
\hline Cue Type $\times$ SOA $\times$ Validity & 17 & 25.47 & $<.001$ & .60 \\
\hline Cue Type $\times$ Validity $\times$ Cue Match & 17 & 21.2 & $<.001$ & .56 \\
\hline \multicolumn{5}{|l|}{ Experiment 3} \\
\hline Target Type & 19 & 514.06 & $<.001$ & .96 \\
\hline Validity & 19 & 6.82 & .017 & .26 \\
\hline Cue Match & 19 & 22.50 & $<.001$ & .54 \\
\hline Target Type $\times$ SOA & 19 & 4.96 & .038 & .21 \\
\hline SOA $\times$ Validity & 19 & 39.35 & $<.001$ & .67 \\
\hline Target Type $\times$ Cue Match & 19 & 15.83 & $<.001$ & .45 \\
\hline Validity $\times$ Cue Match & 19 & 38.16 & $<.001$ & .67 \\
\hline Target Type $\times$ SOA $\times$ Validity & 19 & 8.39 & .009 & .31 \\
\hline Target Type $\times$ Validity $\times$ Cue Match & 19 & 19.79 & $<.001$ & .51 \\
\hline \multicolumn{5}{|l|}{ Experiment 4} \\
\hline Cue Match & 19 & 47.12 & $<.001$ & .71 \\
\hline Cue Type $\times$ SOA & 19 & 4.98 & .038 & .21 \\
\hline SOA $\times$ Validity & 19 & 13.15 & .002 & .41 \\
\hline Validity $\times$ Cue Match & 19 & 88.10 & $<.001$ & .82 \\
\hline \multicolumn{5}{|l|}{ Experiment 5} \\
\hline Cue Match & 17 & 31.15 & $<.001$ & .65 \\
\hline SOA $\times$ Validity & 17 & 100.62 & $<.001$ & .86 \\
\hline Validity $\times$ Cue Match & 17 & 68.84 & $<.001$ & .80 \\
\hline
\end{tabular}


Table 3 All significant main effects and interactions of analyses of variance with mean accuracy rates of Experiments 1a-5

\begin{tabular}{|c|c|c|c|c|}
\hline Significant main effects and interactions & $d f$ & $F$ & $p$ & $\eta_{p}^{2}$ \\
\hline \multicolumn{5}{|l|}{ Experiment 1a } \\
\hline Validity & 20 & 20.27 & $<.001$ & .50 \\
\hline Cue Type $\times$ Validity & 20 & 29.04 & $<.001$ & .59 \\
\hline Cue Type $\times$ Validity $\times$ Cue Match & 20 & 23.18 & $<.001$ & .54 \\
\hline SOA $\times$ Validity $\times$ Cue Match & 20 & 12.38 & .002 & .38 \\
\hline \multicolumn{5}{|l|}{ Experiment $1 \mathrm{~b}$} \\
\hline Validity & 19 & 28.01 & $<.001$ & 60 \\
\hline Cue Type $\times$ Validity & 19 & 11.62 & .003 & .38 \\
\hline Cue Type $\times$ SOA $\times$ Validity & 19 & 29.60 & $<.001$ & .61 \\
\hline Cue Type $\times$ Validity $\times$ Cue Match & 19 & 5.89 & .025 & .24 \\
\hline Cue Type $\times$ SOA $\times$ Validity $\times$ Cue Match & 19 & 5.41 & .031 & .22 \\
\hline \multicolumn{5}{|l|}{ Experiment 2} \\
\hline Validity & 17 & 5.74 & .028 & .25 \\
\hline Cue Match & 17 & 11.45 & .004 & .40 \\
\hline Validity $\times$ Cue Match & 17 & 28.36 & $<.001$ & .63 \\
\hline \multicolumn{5}{|l|}{ Experiment 3} \\
\hline Target Type & 19 & 118.45 & $<.001$ & .86 \\
\hline Target Type $\times$ Cue Match & 19 & 7.19 & .015 & .27 \\
\hline Target Type $\times$ Validity $\times$ Cue Match & 19 & 7.89 & .011 & .29 \\
\hline \multicolumn{5}{|l|}{ Experiment 4} \\
\hline Cue Match & 19 & 24.93 & $<.001$ & .57 \\
\hline SOA $\times$ Validity & 19 & 7.22 & .015 & .28 \\
\hline Validity $\times$ Cue Match & 19 & 55.64 & $<.011$ & .75 \\
\hline \multicolumn{5}{|l|}{ Experiment 5} \\
\hline Cue Match & 17 & 8.40 & .001 & .33 \\
\hline SOA $\times$ Validity & 17 & 15.26 & .001 & .47 \\
\hline Validity $\times$ Cue Match & 17 & 14.10 & .002 & .45 \\
\hline
\end{tabular}

Table 4 All significant main effects and interactions of the conducted analysis of variance with mean correct reaction times of Experiments 3 including the additional fifth factor target type in trial $n-1$

\begin{tabular}{|c|c|c|c|c|}
\hline Significant main effects and interactions & $d f$ & $F$ & $p$ & $\eta_{p}^{2}$ \\
\hline Target Type & 19 & 524.14 & $<.001$ & .97 \\
\hline Validity & 19 & 7.19 & .015 & .27 \\
\hline Cue Match & 19 & 22.37 & $<.001$ & .54 \\
\hline Target Type $\times$ SOA & 19 & 4.52 & .047 & .19 \\
\hline SOA $\times$ Validity & 19 & 40.38 & $<.001$ & .68 \\
\hline Target Type $\times$ Cue Match & 19 & 15.01 & .001 & .44 \\
\hline Validity $\times$ Cue Match & 19 & 37.97 & $<.001$ & .67 \\
\hline Target Type $\times$ Target Type in Trial $N-1$ & 19 & 53.44 & $<.001$ & .74 \\
\hline Target Type $\times$ SOA $\times$ Validity & 19 & 7.74 & .012 & .29 \\
\hline Target Type $\times$ Validity $\times$ Cue Match & 19 & 19.51 & $<.001$ & .51 \\
\hline
\end{tabular}




\section{Appendix C}

Listing of mean correct reaction times and accuracy rates of Experiments $1 \mathrm{a}-5$ as a function of the respective factors

Table 5 Reaction times (RTs; in ms) and accuracy rates (ACCs; in \%) of Experiment 1a as a function of the factors cue type, stimulus-onset asynchrony (SOA), cue match, and validity

\begin{tabular}{|c|c|c|c|c|c|}
\hline \multicolumn{6}{|l|}{ Experiment 1a } \\
\hline Cue type & SOA & Cue match & Validity & RT & ACC \\
\hline \multirow[t]{8}{*}{ Color-ring cue } & \multirow[t]{4}{*}{ Short SOA } & \multirow[t]{2}{*}{ Matching } & Valid & 499 & 97.8 \\
\hline & & & Invalid & 586 & 92.6 \\
\hline & & \multirow[t]{2}{*}{ Nonmatching } & Valid & 555 & 97.6 \\
\hline & & & Invalid & 554 & 94.8 \\
\hline & \multirow[t]{4}{*}{ Long SOA } & \multirow[t]{2}{*}{ Matching } & Valid & 546 & 98.0 \\
\hline & & & Invalid & 582 & 93.2 \\
\hline & & \multirow[t]{2}{*}{ Nonmatching } & Valid & 562 & 95.2 \\
\hline & & & Invalid & 563 & 95.7 \\
\hline \multirow[t]{8}{*}{ Color-word cue } & \multirow[t]{4}{*}{ Short SOA } & \multirow[t]{2}{*}{ Matching } & Valid & 575 & 90.5 \\
\hline & & & Invalid & 552 & 96.3 \\
\hline & & \multirow[t]{2}{*}{ Nonmatching } & Valid & 561 & 96.2 \\
\hline & & & Invalid & 554 & 95.0 \\
\hline & \multirow[t]{4}{*}{ Long SOA } & \multirow[t]{2}{*}{ Matching } & Valid & 558 & 95.4 \\
\hline & & & Invalid & 558 & 96.0 \\
\hline & & \multirow[t]{2}{*}{ Nonmatching } & Valid & 567 & 94.8 \\
\hline & & & Invalid & 559 & 96.2 \\
\hline
\end{tabular}

Table 6 Reaction times (RTs; in ms) and accuracy rates (ACCs; in \%) of Experiment $1 \mathrm{~b}$ as a function of the factors cue type, stimulus-onset asynchrony (SOA), cue match, and validity

\begin{tabular}{llllll}
\hline Experiment 1b & & & & & \\
\hline Cue type & \multirow{2}{*}{ SOA } & Cue match & Validity & RT & ACC \\
\hline Color-ring cue & \multirow{2}{*}{ Short SOA } & \multirow{2}{*}{ Matching } & Valid & 525 & 96.9 \\
& & & Invalid & 643 & 88.7 \\
& & \multirow{2}{*}{ Nonmatching } & Valid & 592 & 94.8 \\
& \multirow{4}{*}{ Long SOA } & \multirow{2}{*}{ Matching } & Invalid & 591 & 91.3 \\
& & & Valid & 579 & 93.5 \\
& & \multirow{2}{*}{ Nonmatching } & Valid & 603 & 92.9 \\
& & & Invalid & 597 & 93.0 \\
Symbolic cue & \multirow{2}{*}{ Short SOA } & \multirow{2}{*}{ Matching } & Valid & 608 & 92.3 \\
& & & Invalid & 580 & 95.1 \\
& & \multirow{2}{*}{ Nonmatching } & Valid & 590 & 92.9 \\
& & & Invalid & 574 & 93.5 \\
& \multirow{2}{*}{ Long SOA } & Matching & Valid & 599 & 92.7 \\
& & & Invalid & 598 & 90.8 \\
& & \multirow{2}{*}{ Nonmatching } & Valid & 609 & 92.7 \\
& & & Invalid & 602 & 93.3
\end{tabular}

Table 7 Reaction times (RTs; in ms) and accuracy rates (ACCs; in \%) of Experiment 2 as a function of the factors cue type, stimulus-onset asynchrony (SOA), cue match, and validity

\begin{tabular}{|c|c|c|c|c|c|}
\hline \multicolumn{6}{|l|}{ Experiment 2} \\
\hline Cue type & SOA & Cue match & Validity & RT & ACC \\
\hline \multirow[t]{8}{*}{ Color-ring cue } & \multirow[t]{4}{*}{ Short SOA } & \multirow[t]{2}{*}{ Matching } & Valid & 802 & 95.6 \\
\hline & & & Invalid & 822 & 93.0 \\
\hline & & \multirow[t]{2}{*}{ Nonmatching } & Valid & 832 & 91.0 \\
\hline & & & Invalid & 811 & 93.1 \\
\hline & \multirow[t]{4}{*}{ Long SOA } & \multirow[t]{2}{*}{ Matching } & Valid & 817 & 95.6 \\
\hline & & & Invalid & 827 & 92.8 \\
\hline & & \multirow[t]{2}{*}{ Nonmatching } & Valid & 844 & 92.1 \\
\hline & & & Invalid & 817 & 92.7 \\
\hline \multirow[t]{8}{*}{ Color-word cue } & \multirow[t]{4}{*}{ Short SOA } & \multirow[t]{2}{*}{ Matching } & Valid & 740 & 94.9 \\
\hline & & & Invalid & 875 & 90.0 \\
\hline & & \multirow[t]{2}{*}{ Nonmatching } & Valid & 855 & 88.0 \\
\hline & & & Invalid & 834 & 92.3 \\
\hline & \multirow[t]{4}{*}{ Long SOA } & \multirow[t]{2}{*}{ Matching } & Valid & 814 & 94.0 \\
\hline & & & Invalid & 821 & 92.9 \\
\hline & & \multirow[t]{2}{*}{ Nonmatching } & Valid & 920 & 89.4 \\
\hline & & & Invalid & 793 & 95.0 \\
\hline
\end{tabular}

Table 8 Reaction times (RTs; in ms) and accuracy rates (ACCs; in \%) of Experiment 3 as a function of the factors target type, stimulus-onset asynchrony (SOA), cue match, and validity

Experiment 3

\begin{tabular}{llllll}
\hline Target Type & \multirow{2}{*}{ SOA } & \multirow{2}{*}{ Cue Match } & Validity & RT & ACC \\
\hline color-ring target & \multirow{2}{*}{ short SOA } & \multirow{2}{*}{ matching } & valid & 567 & 95.2 \\
& & & invalid & 613 & 95.6 \\
& & \multirow{2}{*}{ nonmatching } & valid & 571 & 97.9 \\
& \multirow{2}{*}{ long SOA } & \multirow{2}{*}{ matching } & invalid & 607 & 95.5 \\
& & & valid & 582 & 96.7 \\
& & \multirow{2}{*}{ nonmatching } & invalid & 587 & 95.5 \\
& & & valid & 589 & 95.6 \\
color-word target & \multirow{2}{*}{ short SOA } & matching & valid & 751 & 89.4 \\
& & & invalid & 864 & 84.2 \\
& & \multirow{2}{*}{ nonmatching } & valid & 829 & 83.1 \\
& & & invalid & 834 & 85.6 \\
& \multirow{2}{*}{ long SOA } & matching & valid & 818 & 89.0 \\
& & & invalid & 831 & 89.0 \\
& & \multirow{2}{*}{ nonmatching } & valid & 881 & 83.3 \\
& & & invalid & 820 & 88.5 \\
\hline & & & & &
\end{tabular}


Table 9 Reaction times (RTs; in ms) and accuracy rates (ACCs; in \%) of Experiment 4 as a function of the factors cue type, stimulus-onset asynchrony (SOA), cue match, and validity

\begin{tabular}{|c|c|c|c|c|c|}
\hline Cue type & SOA & Cue match & Validity & RT & $\mathrm{ACC}$ \\
\hline \multirow[t]{8}{*}{ Dissimilar font } & \multirow[t]{4}{*}{ Short SOA } & \multirow[t]{2}{*}{ Matching } & Valid & 756 & 87.4 \\
\hline & & & Invalid & 852 & 86.6 \\
\hline & & \multirow[t]{2}{*}{ Nonmatching } & Valid & 855 & 77.9 \\
\hline & & & Invalid & 824 & 85.7 \\
\hline & \multirow[t]{4}{*}{ Long SOA } & \multirow[t]{2}{*}{ Matching } & Valid & 789 & 87.5 \\
\hline & & & Invalid & 811 & 87.3 \\
\hline & & \multirow[t]{2}{*}{ Nonmatching } & Valid & 850 & 83.3 \\
\hline & & & Invalid & 801 & 88.5 \\
\hline \multirow[t]{8}{*}{ Similar font } & \multirow[t]{4}{*}{ Short SOA } & \multirow[t]{2}{*}{ Matching } & Valid & 747 & 91.9 \\
\hline & & & Invalid & 855 & 84.9 \\
\hline & & \multirow[t]{2}{*}{ Nonmatching } & Valid & 838 & 84.4 \\
\hline & & & Invalid & 823 & 86.0 \\
\hline & \multirow[t]{4}{*}{ Long SOA } & \multirow[t]{2}{*}{ Matching } & Valid & 788 & 88.3 \\
\hline & & & Invalid & 827 & 87.8 \\
\hline & & \multirow[t]{2}{*}{ Nonmatching } & Valid & 877 & 81.7 \\
\hline & & & Invalid & 799 & 89.4 \\
\hline
\end{tabular}

Table 10 Reaction times (RTs; in ms) and accuracy rates (ACCs; in \%) of Experiment 5 as a function of the factors block, stimulus-onset asynchrony (SOA), cue match, and validity

\begin{tabular}{|c|c|c|c|c|c|}
\hline \multicolumn{6}{|l|}{ Experiment 5} \\
\hline Block & SOA & Cue match & Validity & RT & $\mathrm{ACC}$ \\
\hline \multirow[t]{8}{*}{ Syllable repetition } & \multirow[t]{4}{*}{ Short SOA } & \multirow[t]{2}{*}{ Matching } & Valid & 751 & 90.6 \\
\hline & & & Invalid & 862 & 85.4 \\
\hline & & \multirow[t]{2}{*}{ Nonmatching } & Valid & 828 & 86.6 \\
\hline & & & Invalid & 839 & 88.0 \\
\hline & \multirow[t]{4}{*}{ Long SOA } & \multirow[t]{2}{*}{ Matching } & Valid & 795 & 90.0 \\
\hline & & & Invalid & 798 & 90.3 \\
\hline & & \multirow[t]{2}{*}{ Nonmatching } & Valid & 866 & 85.4 \\
\hline & & & Invalid & 773 & 91.7 \\
\hline \multirow[t]{8}{*}{ Foot tapping } & \multirow[t]{4}{*}{ Short SOA } & \multirow[t]{2}{*}{ Matching } & Valid & 778 & 90.7 \\
\hline & & & Invalid & 866 & 87.0 \\
\hline & & \multirow[t]{2}{*}{ Nonmatching } & Valid & 850 & 86.8 \\
\hline & & & Invalid & 848 & 87.3 \\
\hline & \multirow[t]{4}{*}{ Long SOA } & \multirow[t]{2}{*}{ Matching } & Valid & 818 & 90.5 \\
\hline & & & Invalid & 822 & 89.7 \\
\hline & & \multirow[t]{2}{*}{ Nonmatching } & Valid & 891 & 81.0 \\
\hline & & & Invalid & 820 & 90.9 \\
\hline
\end{tabular}

\section{Appendix D}

Listing of post hoc comparisons of RTs between valid matching and nonmatching cues, as well as between invalid matching and nonmatching cues, from Experiments 1a-5

\section{Experiment 1a}

Reflecting the contingent-capture effects, a selective validity effect for matching and its absence for nonmatching color-ring cues was found in the short SOA: RTs were faster in valid matching than valid in nonmatching $(555 \mathrm{~ms})$ conditions, $t(20)=-9.53, p<.001, d=-2.03$, and RTs were slower in invalid matching than in invalid nonmatching $(554 \mathrm{~ms})$ conditions, $t(20)=6.28, p<.001, d=1.34$. With the long SOA, in invalid conditions, RTs for nonmatching cues $(563 \mathrm{~ms})$ were also significantly faster than for matching cues, $t(20)=3.81, p$ $=.001, d=0.81$. There was no significant difference between valid matching and nonmatching color-ring cues, $t(20)=$ $-2.32, p=.031, d=-0.49$. Color-word cues did not produce any significant effects, all $|t \mathrm{~s}|(20)<2.26$, all $p \mathrm{~s}>.035$, all $|d \mathrm{~s}|<$ 0.48 .

\section{Experiment 1b}

For color-ring cues, in the short SOA condition, RTs were faster in valid matching than in nonmatching $(592 \mathrm{~ms})$ conditions, $t(19)=-6.99, p<.001, d=-1.53$, and RTs were slower in invalid matching than in nonmatching $(591 \mathrm{~ms})$ conditions, $t(19)=6.51, p<.001, d=1.42$. The same pattern arose in the long SOA, faster RTs after valid matching than after nonmatching cues $(603 \mathrm{~ms}), t(19)=-4.00, p<.001, d=$ -0.87 , as well as slower RTs after invalid matching than after nonmatching cues (597 ms), $t(19)=5.57, p<.001, d=1.22$. For symbolic cues, no further effects were found, all nonsignificant, $|t \mathrm{~s}|(19)<2.12$, all $p \mathrm{~s}>.048$, all $|d \mathrm{~s}|<0.46$.

\section{Experiment 2}

Reflecting contingent-capture effect, for color-word cues, RTs were also faster in valid matching $(776 \mathrm{~ms})$ than valid nonmatching (888 ms) conditions, $t(17)=-7.57, p<.001, d$ $=-1.74$, and slower in invalid matching $(847 \mathrm{~ms})$ than in invalid nonmatching $(813 \mathrm{~ms}$ ) conditions, $t(17)=6.58, p<$ $.001, d=1.51$. For color-ring cues, no further effects were significant, all $|t \mathrm{~s}|(17)<2.38$, all $p \mathrm{~s}>.029$, all $|d \mathrm{~s}|<0.55$.

\section{Experiment 3}

Related to the same nonsignificant influence of cue match on validity, in color-ring target trials, there was neither a significant difference between valid matching and valid nonmatching conditions, nor between invalid matching and 
invalid nonmatching conditions, all nonsignificant $|t \mathrm{~s}|(19)<$ 2.77 , all $p \mathrm{~s}>.012$, all $|d \mathrm{~s}|<0.60$. In color-word target trials, the validity effect difference was reflected in faster RTs for valid matching (785 $\mathrm{ms})$ than for valid nonmatching (855 ms) conditions, $t(19)=-5.12, p<.001, d=-1.12$, and slower RTs for invalid matching $(847 \mathrm{~ms})$ than for invalid nonmatching $(827 \mathrm{~ms})$ conditions, $t(19)=3.97, p=.001, d$ $=0.87$.

\section{Experiment 4}

In valid conditions, we found faster RTs for matching than for nonmatching cues, $t(19)=-5.93, p<.001, d=-1.29$, and in invalid conditions slower RTs for matching than for nonmatching cues, $t(19)=3.74, p=.001, d=0.82$.

\section{Experiment 5}

In valid conditions, RTs were faster for matching (786 ms) than for nonmatching (858 ms) cues, $t(17)=-7.50, p<$ $.001, d=-1.72$. In invalid conditions, RTs were slower for matching (836 ms) than for nonmatching (819 ms) cues, $t(17)$ $=3.92, p=.001, d=0.90$.

\section{Appendix E}

Post hoc comparisons of ACCs between valid matching and nonmatching cues, as well as between invalid matching and nonmatching cues, from Experiments $1 \mathrm{a}-5$

\section{Experiment 1a}

With color-ring cues-reflecting the contingent-capture effect - in invalid conditions, more errors were made with matching cues than with nonmatching cues (accuracy rate: $95.2 \%), t(20)=-3.60, p=.002, d=-0.77$. Only, the better performance for matching than for nonmatching cues in valid conditions was not significant, $t(20)=1.97, p=.063, d=0.42$. For color-word cues, there were no significant effects, all $|t \mathrm{~s}|(20)<2.13$, all $p \mathrm{~s}>.046$, all $|d \mathrm{~s}|<0.45$.

\section{Experiment 1b}

No further significant effects were found, neither for colorring cues, all $|t \mathrm{~s}|(19)<2.08$, all $p \mathrm{~s}>.051$, all $|d \mathrm{~s}|<0.45$, nor for symbolic cues, all $|t \mathrm{~s}|(19)<2.79$, all $p \mathrm{~s}>.012$, all $|d \mathrm{~s}|<$ 0.61 .

\section{Experiment 2}

Related to the contingent-capture effect, in the valid condition, fewer errors were made with a matching cue than with a nonmatching cue, $t(17)=4.96, p<.001, d=1.14$. In the invalid condition, there was no significant difference in performance between matching and nonmatching cues, $t(17)$ $=-2.74, p=.014, d=-0.63$.

\section{Experiment 3}

There were no further significant effects, either with colorword targets, all $|t \mathrm{~s}|(19)<3.02$, all $p \mathrm{~s}>.007$, all $|d \mathrm{~s}|<0.66$, or with color-ring targets, all $|t \mathrm{~s}|(19)<0.44$, all $p \mathrm{~s}>.664$, all $|d \mathrm{~s}|<0.10$.

\section{Experiment 4}

For valid conditions, there was a significantly higher accuracy after matching than after nonmatching cues, $t(19)=7.46, p<$ $.001, d=1.63$, but in invalid conditions, there was no significant difference in performance for matching versus nonmatching cues, $t(19)=-1.05, p=.307, d=-0.23$.

\section{Experiment 5}

In valid conditions, we found significantly higher accuracies with matching $(90.5 \%)$ than with nonmatching cues, $t(17)=$ $4.15, p=.001, d=0.95$. However, in invalid conditions, there was no significant difference for matching $(88.1 \%)$ versus nonmatching cues, $t(17)=-1.57, p=.135, d=-0.36$.

\section{Appendix F}

Additional analysis and discussion of Experiment 3

\section{Additional analysis of task-switch costs in Experiment 3}

To investigate if the trial-by-trial change of target type required a change of the search template, we looked for switch costs between alternative task representations (cf. Monsell, 2003) - here, between different search templates. We also tested if this kind of template switching could have affected the degree to which the cues captured attention. Maybe attention capture by the matching color-word cues was stronger following a target-word trial than following a color-ring target trial. Therefore, an ANOVA of the correct mean reaction times with target type (color-word target vs. color-ring target), validity (valid vs. invalid), cue match (matching vs. nonmatching), and with an additional fifth variable target type in trial $n-1$ (word target in trial $n-1$ vs. color-ring target in trial $n-1$ ) was conducted. The results remained unchanged, except for a further significant two-way interaction of target type in $n$ and target type in $n-1, F(1,19)=53.44, p<.001, \eta_{p}^{2}$ $=.74$, reflecting switch costs (see Table 4 in Appendix B for a complete listing of all significant main effects and interactions). Where the target type changed across subsequent trials, participants reacted significantly slower than 
where it repeated, both for color-ring targets, $t(19)=5.92, p<$ $.001, d=1.29$ (change: $603 \mathrm{~ms}$, repeat: $583 \mathrm{~ms}$ ), and colorword targets, $t(19)=3.90, p<.001, d=0.85$ (change: $839 \mathrm{~ms}$, repeat: $826 \mathrm{~ms}$ ). The alpha level was Bonferroni corrected for two comparisons $(\alpha=.025)$.

\section{Discussion of the nonselective validity effect of color-word cues in Experiment 3}

Overall faster responses in color-ring target conditions than in color-word target conditions (see Fig. 11; Table 8 in Appendix C) suggested that, at an early stage of processing, all colorword cues captured attention, regardless of the match of their meaning to the specific target templates, and that a stronger validity effect of the matching than of the nonmatching colorword cues in color-word target trials must have subsequently built up across time from this initial general word-based validity effect. According to this reasoning, only in the case of the slower responses to the color-word targets would sufficient time have passed so that the slower top-down contingency based on color-word meaning did show up (see also X. Wu, Liu, \& Fu, 2016).

This pattern of results would be in line with Theeuwes, Atchley, and Kramer's (2000) rapid disengagement model. According to this explanation, any salient singleton (here, the color-word cue) initially captures attention, and subsequently only the less target-similar nonmatching cue, but not the more target-similar matching cue, would be suppressed sufficiently quickly, so that ultimately only the more difficult to suppress capture by the matching cues would be reflected in a validity effect (see also Gaspelin et al., 2016). ${ }^{3}$ However, different from Theeuwes et al.'s rapid disengagement model, in the current study, early capture by all color-word cues was most likely not due to the bottom-up salience of the colorword cues but rather reflected a form of top-down contingency. In the present study, validity effects by the color-word cues were not observed during search for color-ring targets in Experiment 1a, in which participants did not also search for color-word targets at the same time and in which the colorword cues were therefore task irrelevant. Yet a true bottom-up capture effect by the salient color-word cues should have

\footnotetext{
$\overline{3}$ One might wonder why there was no significant interaction between cue match, SOA, and validity if rapid disengagement accounted for the difference between the validity effect of the matching color-word cues and the lack of a validity effect with the nonmatching color-word cues. This was probably because by the time of the color-word target responses in the short SOA condition, the maximal head start of disengagement from nonmatching relative to disengagement by matching cues has already been reached. As a consequence, the difference between nonmatching and matching cues did not increase further in the additional time since cue onset and before response that was provided by the longer SOA. Rather, numerically, for both the matching and the nonmatching color-word cues the disengagement proceeded to a similar degree in the additional time from the short SOA to the long SOA (see Fig. 7; see also Figs. 11 and 13 for supporting evidence in a less complicated search task, with only color-word targets).
}

shown up in Experiment 1a, too, regardless of the task relevance of the color words. Thus, it is likely that the validity effect of all color-word cues in the color-ring target trials of the present experiment reflected a type of top-down contingent capture-for example, a general sensitivity of top-down templates during search for only particular color words for either letters, words, color meanings, or a combination of these.

This conclusion was also supported by an additional analysis of the RTs in which we tested if trial-by-trial switches from one target type to the other target type led to a switch cost indicative of separate search templates for the two targets. Although this analysis indicated that search was faster where the same types of targets were used in subsequent trials than where the type of target had switched from the preceding trial, the validity effect of the word cues was not further affected by this (cf. Büsel, Pomper, et al., 2018a; Irons et al., 2011). This ruled out that word-cue capture was due to intertrial priming by word targets in $n-1$ (cf. Theeuwes, 2013, 2018). If priming by word targets in trial $n-1$ would have been responsible for word-cue capture, we would have expected the word cues' validity effects to be stronger or selectively present following a word-target trial. As the interaction between target type in $n-1$ and validity was far from significant, $F(1,19)=72.37, p=.140$, we can rule out an intertrial priming account, in turn supporting a topdown interpretation of the word cues' validity effect.

The remaining switch costs following a trial-by-trial change of the target types thus also suggested that the search sets responsible for the cue-word validity effect were not the same as those that participants ultimately used to select the word targets. Maybe participants first searched for letters or for words, regardless of their meanings, accounting for the validity effect of all word cues, and only then participants also scrutinized word meanings, allocating attention more at meaning-matching cues but rejecting cues that did not match the target words' meaning. On top of that, the onset of a colorring target display might have led to the efficient suppression of all words.

To note, however, conditions in Experiment 3 were special in that half of all trials allowed relatively swift color-ring search instead of slower color-word search. Maybe a two-step, top-down strategy of first selecting all words in a top-down way, and only initiating a discrimination between target and distractor words when this was necessary, was encouraged by the fact that very often a deeper going processing of the words was not required (i.e., in the color-ring target trials of Experiment 3). Therefore, we do not want to rule out that contingent capture by matching color-word cues only, and based on search templates for only particular color-word targets, is at work where each and every trial requires searching for a particular word - that is, under conditions as in Experiment 2. 
Open Access This article is distributed under the terms of the Creative Commons Attribution 4.0 International License (http:// creativecommons.org/licenses/by/4.0/), which permits unrestricted use, distribution, and reproduction in any medium, provided you give appropriate credit to the original author(s) and the source, provide a link to the Creative Commons license, and indicate if changes were made.

\section{References}

Ansorge, U., \& Horstmann, G. (2007). Preemptive control of attentional capture by colour: Evidence from trial-by-trial analyses and orderings of onsets of capture effects in reaction time distributions. Quarterly Journal of Experimental Psychology, 60, 952-975. https://doi.org/10.1080/17470210600822795

Ansorge, U., Kiss, M., Worschech, F., \& Eimer, M. (2011). The initial stage of visual selection is controlled by top-down task set: New ERP evidence. Attention, Perception, \& Psychophysics, 73, 113122. https://doi.org/10.3758/s13414-010-0008-3

Ansorge, U., Priess, H., \& Kerzel, D. (2013). Effects of relevant and irrelevant color singletons on inhibition of return and attentional capture. Attention, Perception, \& Psychophysics, 75, 1687-702. https://doi.org/10.3758/s13414-013-0521-2

Ariga, A., \& Yokosawa, K. (2008). Contingent attentional capture occurs by activated target congruence. Perception \& Psychophysics, 70, 680-687. https://doi.org/10.3758/PP.70.4.680

Bacon, W. F., \& Egeth, H. E. (1994). Overriding stimulus-driven attentional capture. Perception \& Psychophysics, 55, 485-496. https:// doi.org/10.3758/BF03205306

Baddeley, A. D. (1986). Working memory. Oxford, UK: Oxford University Press.

Baddeley, A. D., Lewis, V., \& Vallar, G. (1984). Exploring the articulatory loop. Quarterly Journal of Experimental Psychology: Section A, 36, 233-252. https://doi.org/10.1080/ 14640748408402157

Barsalou, L. W. (1999). Perceptual symbol systems. Behavioral and Brain Sciences, 22, 577-660. https://doi.org/10.1017/ S0140525X99002149

Belke, E., Humphreys, G. W., Watson, D. G., Meyer, A. S., \& Telling, A. L. (2008). Top-down effects of semantic knowledge in visual search are modulated by cognitive but not perceptual load. Perception \& Psychophysics, 70, 1444-1458. https://doi.org/10.3758/PP.70.8. 1444

Belopolsky, A. V., Schreij, D., \& Theeuwes, J. (2010). What is top-down about contingent capture? Attention, Perception, \& Psychophysics, 72, 326-341. https://doi.org/10.3758/APP.72.2.326

Berggren, N., \& Eimer, M. (2016). Does contralateral delay activity reflect working memory storage or the current focus of spatial attention within visual working memory? Journal of Cognitive Neuroscience, 28, 2003-2020. https://doi.org/10.1162/jocn_a 01019

Biderman, D., Biderman, N., Zivony, A., \& Lamy, D. (2017). Contingent capture is weakened in search for multiple features from different dimensions. Journal of Experimental Psychology: Human Perception and Performance, 43, 1974-1992. https://doi.org/10. 1037/xhp0000422

Bradshaw, J. L. (1974). Peripherally presented and unreported words may bias the perceived meaning of a centrally fixated homograph. Journal of Experimental Psychology, 103, 1200-1202. https://doi. org/10.1037/h0037371

Büsel, C., Pomper, U., \& Ansorge, U. (2018a). Capture of attention by target-similar cues during dual-color search reflects reactive control among top-down selected attentional control settings. Psychonomic Bulletin \& Review. Advance online publication. https://doi.org/10. 3758/s13423-018-1543-5
Büsel, C., Voracek, M., \& Ansorge, U. (2018b). A meta-analysis of contingent-capture effects. Psychological Research. Advance online publication. https://doi.org/10.1007/s00426-018-1087-3

Bundesen, C. (1990). A theory of visual attention. Psychological Review, 97, 523-547. https://doi.org/10.1037/0033-295X.97.4.523

Carlisle, N. B., Arita, J. T., Pardo, D., \& Woodman, G. F. (2011). Attentional templates in visual working memory. Journal of Neuroscience, 31, 9315-9322. https://doi.org/10.1523/jneurosci. 1097-11.2011

Carmel, T., \& Lamy, D. (2014). The same-location cost is unrelated to attentional settings: An object-updating account. Journal of Experimental Psychology: Human perception and performance, 40, 1465-1478. https://doi.org/10.1037/a0036383

Carmel, T., \& Lamy, D. (2015). Towards a resolution of the attentionalcapture debate. Journal of experimental psychology: Human Perception and Performance, 41, 1772-1782. https://doi.org/10. 1037/xhp0000118

Champely, S. (2017). pwr: Basic functions for power analysis (R Package Version 1.2-1) [Computer software]. Retrieved from https://CRAN. R-project.org/package $=$ pwr

Cohen, J. (1988). Statistical power analysis for the behavioral sciences (2nd ed.). Hillsdale, NJ: Erlbaum.

Coltheart, M., Curtis, B., Atkins, P., \& Haller, M. (1993). Models of reading aloud: Dual-route and parallel-distributed-processing approaches. Psychological Review, 100, 589-608. https://doi.org/10. 1037/0033-295X.100.4.589

Daffron, J. L., \& Davis, G. (2016). Target templates specify visual, not semantic, features to guide search: A marked asymmetry between seeking and ignoring. Attention, Perception, \& Psychophysics, 78, 2049-2065. https://doi.org/10.3758/s13414-016-1094-7

Dalrymple-Alford, E. C. (1968). Interlingual interference in a colornaming task. Psychonomic Science, 10, 215-216. https://doi.org/ 10.3758/BF03331487

Dalrymple-Alford, E. C. (1972). Associative facilitation and interference in the Stroop color-word task. Perception \& Psychophysics, 11, 274-276. https://doi.org/10.3758/BF03210377

Desimone, R., \& Duncan, J. (1995). Neural mechanisms of selective visual attention. Annual Review of Neuroscience, 18, 193-222. https://doi.org/10.1146/annurev.ne.18.030195.001205

Duncan, J., \& Humphreys, G. (1992). Beyond the search surface: Visual search and attentional engagement. Journal of Experimental Psychology: Human Perception and Performance, 18, 578-588. https://doi.org/10.1037/0096-1523.18.2.578

Durgin, F. H. (2000). The reverse Stroop effect. Psychonomic Bulletin \& Review, 7, 121-125. https://doi.org/10.3758/BF03210730

Dyer, F. N. (1973). Interference and facilitation for color naming with separate bilateral presentations of the word and color. Journal of Experimental Psychology, 99, 314-317. https://doi.org/10.1037/ h0035245

Dyer, F. N., \& Severance, L. J. (1973). Stroop interference with successive presentations of separate incongruent words and colors. Journal of Experimental Psychology, 98, 438-439. https://doi.org/10.1037/ h0034353

Eimer, M., \& Kiss, M. (2008). Involuntary attentional capture is determined by task set: Evidence from event-related brain potentials. Journal of Cognitive Neuroscience, 20, 1423-1433. https://doi.org/ 10.1162/jocn.2008.20099

Eimer, M., Kiss, M., Press, C., \& Sauter, D. (2009). The roles of featurespecific task set and bottom-up salience in attentional capture: An ERP study. Journal of Experimental Psychology: Human Perception and Performance, 35, 1316-1328. https://doi.org/10. 1037/a0015872

Enns, J. T., Lleras, A., \& Moore, C. M. (2009). Object updating: A force for perceptual continuity and scene stability in human vision. In R. Nijhawan (Ed.), Problems of space and time in perception and action (pp. 503-520). New York, NY: Cambridge University Press. 
Folk, C. L., \& Remington, R. (1998). Selectivity in distraction by irrelevant featural singletons: Evidence for two forms of attentional capture. Journal of Experimental Psychology: Human Perception and Performance, 24, 847-858. https://doi.org/10.1037/0096-1523.24. 3.847

Folk, C. L., Remington, R. W., \& Johnston, J. C. (1992). Involuntary covert orienting is contingent on attentional control settings. Journal of Experimental Psychology: Human Perception and Performance, 18, 1030-1044. https://doi.org/10.1037/0096-1523. 18.4.1030

Fuchs, I., Theeuwes, J., \& Ansorge, U. (2013). Exogenous attentional capture by subliminal abrupt-onset cues: Evidence from contrastpolarity independent cueing effects. Journal of Experimental Psychology: Human Perception and Performance, 39, 974-988. https://doi.org/10.1037/a0030419

Gaspelin, N., Ruthruff, E., \& Lien, M. C. (2016). The problem of latent attentional capture: Easy visual search conceals capture by taskirrelevant abrupt onsets. Journal of Experimental Psychology: Human Perception and Performance, 42, 1104-1120. https://doi. org/10.1037/xhp0000214

Gatti, S. V., \& Egeth, H. E. (1978). Failure of spatial selectivity in vision. Bulletin of the Psychonomic Society, 11, 181-184. https://doi.org/10. 3758/BF03336801

Gibson, B. S., \& Amelio, J. (2000). Inhibition of return and attentional control settings. Perception \& Psychophysics, 62, 496-504. https:// doi.org/10.3758/BF03212101

Glaser, W. R., \& Glaser, M. O. (1989). Context effects in Stroop-like word and picture processing. Journal of Experimental Psychology: General, 118, 13-42. https://doi.org/10.1037/0096-3445.118.1.13

Goller, F., Ditye, T., \& Ansorge, U. (2016). The contribution of color to attention capture effects during search for onset targets. Attention, Perception, \& Psychophysics, 78, 789-807. https://doi.org/10.3758/ s13414-015-1053-8

Gromer, D. (2017). apa: Format outputs of statistical tests according to APA guidelines (R Package Version 0.2.0) [Computer software]. Retrieved from https://CRAN.R-project.org/package=apa

Grubert, A., Carlisle, N. B., \& Eimer, M. (2016). The control of singlecolor and multiple-color visual search by attentional templates in working memory and in long-term memory. Journal of Cognitive Neuroscience, 28, 1947-1963. https://doi.org/10.1162/jocn a 01020

Hamker, F. H. (2004). A dynamic model of how feature cues guide spatial attention. Vision Research, 44, 501-521. https://doi.org/10.1016/j. visres.2003.09.033

Hohenstein, S., \& Kliegl, R. (2014). Semantic preview benefit during reading. Journal of Experimental Psychology: Learning, Memory, and Cognition, 40, 166-190. https://doi.org/10.1037/a0033670

Hohenstein, S., Laubrock, J., \& Kliegl, R. (2010). Semantic preview benefit in eye movements during reading: A parafoveal fastpriming study. Journal of Experimental Psychology: Learning, Memory, and Cognition, 36, 1150-1170. https://doi.org/10.1037/ a0020233

Irons, J. L., Folk, C. L., \& Remington, R. W. (2012). All set! Evidence of simultaneous attentional control settings for multiple target colors. Journal of Experimental Psychology: Human Perception and Performance, 38, 758-775. https://doi.org/10.1037/a0026578

Jenkins, M., Grubert, A., \& Eimer, M. (2017). Target objects defined by a conjunction of colour and shape can be selected independently and in parallel. Attention, Perception, \& Psychophysics, 79, 2310-2326. https://doi.org/10.3758/s13414-017-1410-x

Kahneman, D., \& Chajczyk, D. (1983). Tests of the automaticity of reading: Dilution of Stroop effects by color-irrelevant stimuli. Journal of Experimental Psychology: Human Perception and Performance, 9, 497-509. https://doi.org/10.1037/0096-1523.9.4.497
Kerzel, D. (2019). The precision of attentional selection is far worse than the precision of the underlying memory representation. Cognition, 186, 20-31. https://doi.org/10.1016/j.cognition.2019.02.00

Klein, G. S. (1964). Semantic power measured through the interference of words with color-naming. American Journal of Psychology, 77, 576-588. https://doi.org/10.2307/1420768

Kliegl, R., Risse, S., \& Laubrock, J. (2007). Preview benefit and parafoveal-on-foveal effects from word $n+2$. Journal of Experimental Psychology: Human Perception and Performance, 33, 1250-1255. https://doi.org/10.1037/0096-1523.33.5.1250

Lamy, D., Leber, A., \& Egeth, H. E. (2004). Effects of task relevance and stimulus-driven salience in feature-search mode. Journal of Experimental Psychology: Human Perception and Performance, 30, 1019-1031. https://doi.org/10.1037/0096-1523.30.6.1019

Lawrence, M. A. (2016). ez: Easy analysis and visualization of factorial experiments (R Package Version 4.4-0) [Computer software]. Retrieved from https://CRAN.R-project.org/package=ez

Lupyan, G. (2012). Linguistically modulated perception and cognition: The label-feedback hypothesis. Frontiers in Psychology, 3, 54. https://doi.org/10.3389/fpsyg.2012.00054

Lupyan, G., \& Spivey, M. J. (2010). Redundant spoken labels facilitate perception of multiple items. Attention, Perception, \& Psychophysics, 72, 2236-2253. https://doi.org/10.3758/APP.72.8. 2236

MacLeod, C. M. (1991). Half a century of research on the Stroop effect: An integrative review. Psychological Bulletin, 109, 163-203. https://doi.org/10.1037/0033-2909.109.2.163

MacLeod, C. M., \& MacDonald, P. A. (2000). Interdimensional interference in the Stroop effect: Uncovering the cognitive and neural anatomy of attention. Trends in Cognitive Science 4, 383-391. https:// doi.org/10.1016/S1364-6613(00)01530-8

Mast, F., \& Frings, C. (2014). The impact of the irrelevant: The task environment modulates the impact of irrelevant features in response selection. Journal of Experimental Psychology: Human Perception and Performance, 40, 2198-2213. https://doi.org/10.1037/ a0038182

McCauley, C., Parmelee, C. M., Sperber, R. D., \& Carr, T. H. (1980). Early extraction of meaning from pictures and its relation to conscious identification. Journal of Experimental Psychology: Human Perception and Performance, 6, 265-276. https://doi.org/10.1037/ 0096-1523.6.2.265

Ménard-Buteau, C., \& Cavanagh, P. (1984). Localization of form/color interference in perception in a Stroop task with drawn stimuli. Canadian Journal of Psychology, 38, 421-439. https://doi.org/10. 1037/h0080851

Monsell, S. (2003). Task switching. Trends in Cognitive Sciences, 7, 134 140. https://doi.org/10.1016/S1364-6613(03)00028-7

Moores, E., Laiti, L., \& Chelazzi, L. (2003). Associative knowledge controls deployment of visual selective attention. Nature Neuroscience, 6, 182-189. https://doi.org/10.1038/nn996

Nako, R., Smith, T. J., \& Eimer, M. (2016). The role of color in search templates for real-world target objects. Journal of Cognitive Neuroscience, 28, 1714-1727. https://doi.org/10.1162/jocn_a 00996

Naor-Raz, G., Tarr, M. J., \& Kersten, D. (2003). Is color an intrinsic property of object representation? Perception, 32, 667-680. https:// doi.org/10.1068/p5050

Olivers, C. N., Peters, J., Houtkamp, R., \& Roelfsema, P. R. (2011). Different states in visual working memory: When it guides attention and when it does not. Trends in Cognitive Sciences, 15, 327-334. https://doi.org/10.1016/j.tics.2011.05.004

Paap, K. R., Newsome, S. L., \& Noel, R. W. (1984). Word shape's in poor shape for the race to the lexicon. Journal of Experimental Psychology: Human Perception and Performance, 10, 413-428. https://doi.org/10.1037/0096-1523.10.3.413 
Pollatsek, A., Lesch, M., Morris, R. K., \& Rayner, K. (1992). Phonological codes are used in integrating information across saccades in word identification and reading. Journal of Experimental Psychology: Human Perception and Performance, 18, 148-162. https://doi.org/10.1016/10.1037/0096-1523.18.1.148

Posner, M. I., Snyder, C. R. R., \& Davidson, B. J. (1980). Attention and the detection of signals. Journal of Experimental Psychology: General, 109, 160-174. https://doi.org/10.1037/0096-3445.109.2. 160

Rayner, K., McConkie, G. W., \& Zola, D. (1980). Integrating information across eye movements. Cognitive Psychology, 12, 206-226. https:// doi.org/10.1016/0010-0285(80)90009-2

R Core Team. (2017). R: A language and environment for statistical computing. Vienna, Austria: R Foundation for Statistical Computing. Retrieved from https://www.R-project.org/

Saeki, E., \& Saito, S. (2004). The role of the phonological loop in task switching performance: The effect of articulatory suppression in the alternating runs paradigm. Psychologia: International Journal of Psychology in the Orient, 47, 35-43. https://doi.org/10.2117/ psysoc. 2004.35

Schmidt, J., \& Zelinsky, G. J. (2009). Short article: Search guidance is proportional to the categorical specificity of a target cue. Quarterly Journal of Experimental Psychology, 62, 1904-1914. https://doi. org/10.1080/17470210902853530

Schoeberl, T., Ditye, T., \& Ansorge, U. (2017). Same-location costs in peripheral cueing: The role of cue awareness and feature changes. Journal of Experimental Psychology: Human Perception and Performance, 44, 433-451. https://doi.org/10.1037/xhp0000470

Shaffer, W. O., \& LaBerge, D. (1979). Automatic semantic processing of unattended words. Journal of Verbal Learning and Verbal Behavior, 18, 413-426. https://doi.org/10.1016/S0022-5371(79)90228-7

Slattery, T. J., Angele, B., \& Rayner, K. (2011). Eye movements and display change detection during reading. Journal of Experimental Psychology: Human Perception and Performance, 37, 1924-1938. https://doi.org/10.1037/a0024322

Smyth, M. M., \& Scholey, K. A. (1994). Interference in immediate spatial memory. Memory \& Cognition, 22, 1-13. https://doi.org/10.3758/ BF03202756

Stein, T., Zwickel, J., Kitzmantel, M., Ritter, J., \& Schneider, W. X. (2010). Irrelevant words trigger an attentional blink. Experimental Psychology, 57, 301-307. https://doi.org/10.1027/1618-3169/ a000035

Stroop, J. R. (1935). Studies of interference in serial verbal reactions. Journal of Experimental Psychology, 18, 643-662. https://doi.org/ $10.1037 / \mathrm{h} 0054651$

Theeuwes, J. (2013). Feature-based attention: It is all bottom-up priming. Philosophical Transactions of the Royal Society B, 368, 20130055. https://doi.org/10.1098/rstb.2013.0055

Theeuwes, J. (2018). Visual selection: Usually fast and automatic; seldom slow and volitional. Journal of Cognition, 1, 29. https://doi.org/10. 5334/joc. 13

Theeuwes, J., Atchley, P., \& Kramer, A. F. (2000). On the time course of top-down and bottom-up control of visual attention. In S. Monsell \& J. Driver (Eds.), Control of cognitive processes: Attention and performance XVIII (pp. 105-125). Cambridge, MA: MIT Press.
Underwood, G. (1977). Attention, awareness, and hemispheric differences in word recognition. Neuropsychologia, 15, 61-67. https:// doi.org/10.1016/0028-3932(77)90115-4

Vickery, T. J., King, L. W., \& Jiang, Y. (2005). Setting up the target template in visual search. Journal of Vision, 5(1), 81-92. https:// doi.org/10.1167/5.1.8

Walenchok, S. C., Hout, M. C., \& Goldinger, S. D. (2016). Implicit object naming in visual search: Evidence from phonological competition. Attention, Perception, \& Psychophysics, 78, 2633-2654. https://doi. org/10.3758/s13414-016-1184-6

Weekes, N. Y., \& Zaidel, E. (1996). The effects of procedural variations on lateralized Stroop effects. Brain and Cognition, 31, 308-330. https://doi.org/10.1006/brcg.1996.0049

Weywadt, C. R., \& Butler, K. M. (2013). The role of verbal short-term memory in task selection: How articulatory suppression influences task choice in voluntary task switching. Psychonomic Bulletin \& Review, 20, 334-340. https://doi.org/10.3758/s13423-012-0349-0

Wickham, H. (2009). ggplot2: Elegant graphics for data analysis. New York, NY: Springer-Verlag.

Wolfe, J. M., Butcher, S. J., Lee, C., \& Hyle, M. (2003). Changing your mind: On the contributions of top-down and bottom-up guidance in visual search for feature singletons. Journal of Experimental Psychology: Human Perception and Performance, 29, 483-502. https://doi.org/10.1037/0096-1523.29.2.483

Wolfe, J. M., Horowitz, T. S., Kenner, N., Hyle, M., \& Vasan, N. (2004). How fast can you change your mind? The speed of top-down guidance in visual search. Vision Research, 44, 1411-1426. https://doi. org/10.1016/j.visres.2003.11.024

Wu, R., Scerif, G., Aslin, R. N., Smith, T. J., Nako, R., \& Eimer, M. (2013). Searching for something familiar or novel: Top-down attentional selection of specific items or object categories. Journal of Cognitive Neuroscience, 25, 719-729. https://doi.org/10.1162/ jocn_a_00352

Wu, X., Liu, X., \& Fu, S. (2016). Feature-and category-specific attentional control settings are differently affected by attentional engagement in contingent attentional capture. Biological Psychology, 118, 8-16. https://doi.org/10.1016/j.biopsycho.2016.04.065

Wuehr, P., \& Frings, C. (2008). A case for inhibition: Visual attention suppresses the processing of irrelevant objects. Journal of Experimental Psychology: General, 137, 116-130. https://doi.org/ 10.1037/0096-3445.137.1.116

Wyble, B., Folk, C., \& Potter, M. C. (2013). Contingent attentional capture by conceptually relevant images. Journal of Experimental Psychology: Human Perception and Performance, 39, 861-871. https://doi.org/10.1037/a0030517

Yang, H., \& Zelinsky, G. J. (2009). Visual search is guided to categorically-defined targets. Vision Research, 49, 2095-2103. https://doi.org/10.1016/j.visres.2009.05.017

Publisher's note Springer Nature remains neutral with regard to jurisdictional claims in published maps and institutional affiliations. 